\title{
Support to Aviation Control Service (SACS): an online service for near-real-time satellite monitoring of volcanic plumes
}

\author{
H. Brenot ${ }^{1}$, N. Theys ${ }^{1}$, L. Clarisse ${ }^{2}$, J. van Geffen ${ }^{3}$, J. van Gent ${ }^{1}$, M. Van Roozendael ${ }^{1}$, R. van der $A^{3}$, D. Hurtmans ${ }^{2}$,

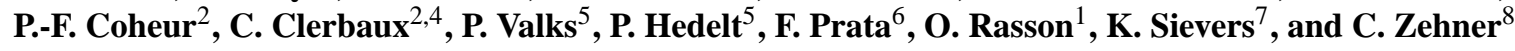 \\ ${ }^{1}$ Belgisch Instituut voor Ruimte-Aeronomie - Institut d'Aéronomie Spatiale de Belgique (BIRA-IASB), Brussels, Belgium \\ ${ }^{2}$ Spectroscopie de l'Atmosphère, Service de Chimie Quantique et Photophysique, Université Libre de Bruxelles (ULB), \\ Brussels, Belgium \\ ${ }^{3}$ Koninklijk Nederlands Meteorologisch Instituut (KNMI), De Bilt, the Netherlands \\ ${ }^{4}$ UPMC Univ. Paris 6; Université de Versailles St.-Quentin, CNRS/INSU, LATMOS-IPSL, Paris, France \\ ${ }^{5}$ Institut für Methodik der Fernerkundung (IMF), Deutsches Zentrum für Luft und Raumfahrt (DLR), Oberpfaffenhofen, \\ Germany \\ ${ }^{6}$ Norsk Institutt for Luftforskning (NILU), Kjeller, Norway \\ ${ }^{7}$ Vereinigung Cockpit - German ALPA, Frankfurt, Germany \\ ${ }^{8}$ European Space Agency (ESA-ESRIN), Frascati, Italy \\ Correspondence to: H. Brenot (brenot@oma.be)
}

Received: 23 August 2013 - Published in Nat. Hazards Earth Syst. Sci. Discuss.: 31 October 2013

Revised: 20 February 2014 - Accepted: 13 March 2014 - Published: 15 May 2014

\begin{abstract}
Volcanic eruptions emit plumes of ash and gases into the atmosphere, potentially at very high altitudes. Ashrich plumes are hazardous for airplanes as ash is very abrasive and easily melts inside their engines. With more than 50 active volcanoes per year and the ever-increasing number of commercial flights, the safety of airplanes is a real concern. Satellite measurements are ideal for monitoring global volcanic activity and, in combination with atmospheric dispersion models, to track and forecast volcanic plumes. Here we present the Support to Aviation Control Service (SACS, http: //sacs.aeronomie.be), which is a free online service initiated by the European Space Agency (ESA) for the near-real-time (NRT) satellite monitoring of volcanic plumes of $\mathrm{SO}_{2}$ and ash. It combines data from three ultraviolet (UV)-visible and three infrared (IR) spectrometers. The UV-vis sensors are the Ozone Monitoring Instrument (OMI) and the Global Ozone Monitoring Experiment-2 (GOME-2) on-board the two polar orbiting meteorological satellites (MetOp-A \& MetOpB) operated by the European Organisation for the Exploitation of Meteorological Satellites (EUMETSAT). The IR sensors are the Atmospheric InfraRed Sounder (AIRS) and the Infrared Atmospheric Sounding Interferometer (IASI) onboard MetOp-A \& MetOp-B. This new multi-sensor warning
\end{abstract}

system of volcanic emissions is based on the selective detection of $\mathrm{SO}_{2}$ and ash. This system is optimised to avoid false alerts while at the same time limiting the number of notifications in case of large plumes. A successful rate with more than $95 \%$ of notifications corresponding to true volcanic activity is obtained by the SACS system.

\section{Volcanic eruptions: a threat to aviation safety}

Volcanic eruptions are known to emit large amounts of aerosols (silicate ash, sulfates and ice particles) and gases (mostly water vapour, $\mathrm{CO}_{2}, \mathrm{SO}_{2}, \mathrm{H}_{2} \mathrm{~S}$ and halogen species). The composition of each volcanic cloud is unique, as it is the result of a complex process driven by the chemistry and motion of magma inside the mantle of the Earth and its ejection at the surface (Robock and Oppenheimer, 2003). Emission can sometimes have severe implications for the atmosphere, life on Earth and human society. Volcanic clouds can have a significant impact on atmospheric chemistry and climate, both locally and on a global scale (Robock, 2000; Oppenheimer et al., 2011), and can strongly affect human health in the vicinity of the volcano, but the effects of a volcanic 
cloud may even be felt far from the volcano (Forbes et al., 2003; Baxter et al., 1999). Volcanic ash and - to a lesser extent - sulfuric gases are also major hazards to aviation. The largest threat to aviation safety is that volcanic ash can damage plane engines and cause them to stall as a result of ash melting (Miller and Casadevall, 1999; Prata, 2009). Volcanic ash can abrade windscreens, damage avionic equipment and navigation systems and reduce the pilots' visibility. Moreover, sulfuric gases, such as $\mathrm{H}_{2} \mathrm{SO}_{4}$ and $\mathrm{SO}_{2}$, may also damage the aircraft (paint and windows) and create sulfate deposits on and inside the engines. The gases might also be dangerous for the health of the passengers. In the past there have been several incidents as a result of encounters of aircraft with volcanic plumes (Casadevall, 1994; Casadevall et al., 1996; Guffanti et al., 2010). A significant difficulty in mitigating volcanic hazards to aviation is that, because of strong winds at high altitudes, fine ash can rapidly be transported over long distances ( $>1000 \mathrm{~km}$ from the volcano) and in the process cross major air routes. As only a small number of the active volcanoes on Earth are regularly monitored using ground equipment, the use of space-based instruments (see Carn et al., 2008, and Thomas and Watson, 2010) is particularly relevant to aviation safety, as it enables the continuous and global monitoring of volcanic plumes in an effective, economical and risk-free way.

Nine worldwide Volcanic Ash Advisory Centres (VAACs) have been designated to advise civil aviation authorities in case of volcanic eruptions. These centres are part of the International Airways Volcano Watch (IAVW), established in 2002 by the International Civil Aviation Organization (ICAO) with the co-operation of numerous countries and several international organisations like the International Atomic Energy Agency (IAEA), the International Air Transport Association (IATA), the International Federation of Air Line Pilots' Associations (IFALPA), the International Union of Geodesy and Geophysics (IUGG) and the World Meteorological Organization (WMO). For more details see ICAO (2012). The nine VAACs each have their own areas of responsibility, which together cover the whole globe. They make advisory information available en route on the extent and movement of volcanic ash in the atmosphere. This information is then used by aviation safety control bodies and by pilots via SIGMET (SIGnificant METeorological Information) advisories. The VAACs provide volcanic ash forecasts using atmospheric dispersion models by making use of all available information on volcanic clouds from observatories, pilot reports and measurements from the ground, aircraft and above all from space instruments (mostly satellite imagery from geostationary instruments).

Until recently, a policy of zero tolerance regarding volcanic ash was applied by ICAO on airlines (Cantor, 1998). This regulation has changed with the introduction of ash concentration thresholds over Europe after the eruptions of the Icelandic volcanoes Eyjafjallajökull in April-May 2010 and Grímsvötn in May 2011, as both caused partial or total clo- sure of airspace over many European countries and led to social and economic upheaval across Europe (IATA, 2010). The introduction of ash concentration thresholds translates into important needs and requirements for improved volcanic ash monitoring and forecasting services (see Zehner et al., 2010). These needs are as follows:

- early detection of volcanic emissions;

- Near real-time (NRT) global monitoring of volcanic plumes, with open access and delivery of data;

- quantitative retrievals of volcanic ash (concentration, altitude and particle size distribution) and $\mathrm{SO}_{2}$ (concentration, altitude) from (but not limited to) satellite instruments; ash data at high temporal resolution from geostationary payloads (Prata and Prata, 2012) have priority;

- accurate source term parameters: time-, particle-sizeand height-resolved ash source emissions for the entire eruptive period;

- improved inversion techniques involving atmospheric models for forecasting ash dispersion and removal (Stohl et al., 2011);

- validation of satellite observations.

In this paper, we give an overview of the Support to Aviation Control Service (SACS) which deals with the first two points listed above as it is an automated global system for the monitoring and warning of volcanic plumes. It makes use of NRT ash and $\mathrm{SO}_{2}$ data products from satellite instruments operating in the ultraviolet (UV)-visible (data from the Ozone Monitoring Instrument (OMI) and the Global Ozone Monitoring Experiment-2 (GOME-2) on-board the two polar orbiting meteorological satellites (MetOp-A and MetOpB) operated by the European Organisation for the Exploitation of Meteorological Satellites (EUMETSAT)) and operating in the thermal infrared (IR) (data from the Atmospheric InfraRed Sounder (AIRS) and the Infrared Atmospheric Sounding Interferometer (IASI) on-board MetOp-A and MetOp-B) wavelength ranges. Note that hereafter instruments on-board MetOp-A and MetOp-B will be respectively referred as GOME-2A, IASI-A and GOME-2B, IASI-B. Using NRT ash and $\mathrm{SO}_{2}$ products, a system has been set up to notify the users by email in case of exceptional volcanic emissions. Here we present the strategy adopted to detect and monitor volcanic clouds. Using examples of recent eruptions, we demonstrate the service, show the information available to the SACS user and detail the different aspects of our work. 


\section{Overview of SACS}

The Support to Aviation Control Service is a project funded by the European Space Agency (ESA) developed within the Data User Element of the Tropospheric Emission Monitoring Internet Service (DUE-TEMIS, http://www.temis.nl) and the PROtocol MOniToring service for the Global Monitoring for Environment and Security (GMES) Service Element (GSEPROMOTE, http://www.gse-promote.org) programmes (Van Geffen et al., 2007). SACS is a collaborative project that currently involves the following partners: the Belgian Institute for Space Aeronomy (BIRA-IASB; leader), the Royal Netherlands Meteorological Institute (KNMI), the University of Brussels (ULB) and the German Aerospace Center (DLR). The SACS project is also indirectly supported by the following agencies/institutions: EUMETSAT (via the Satellite Application Facility on Ozone Monitoring (O3M SAF) program), Centre National d'Etudes Spatiales (CNES), Finnish Meteorological Institute (FMI, Ilmatieteen Laitos), Norsk Institutt for Luftforskning (NILU), Jet Propulsion Laboratory (JPL) and the National Aeronautics and Space Administration (NASA). The primary objective of SACS is to meet the requirements expressed by its users as much as possible, and especially to support the VAACs (key users of the service) in their official task of informing aviation control organisations about the risks associated with volcanic activity. SACS is a free service available through a single, user-friendly web portal (http://sacs.aeronomie.be) that centralises the data (near real time and archive), globally and for a set of predefined regions, in the form of maps (images). This service is also linked to other European initiatives such as the Support to Aviation for Volcanic Ash Avoidance (SAVAA) ESA project (http://savaa.nilu.no), the Volcanic Ash Strategic initiative Team (VAST) ESA project (http://vast.nilu.no) and the European Volcano Observatory Space Services (EVOSS) project of the European Union Framework Programmes EU FP7 (http://www.evoss.eu), whose general aims are to define and demonstrate an optimal system for volcanic ash plume monitoring and prediction.

SACS delivers global data sets for sulfur dioxide $\left(\mathrm{SO}_{2}\right)$ and aerosol (ash) related to volcanic eruptions from measurements by space-based instruments. At the time of writing, SACS is based on polar sun-synchronous satellite instruments widely used to sound atmospheric composition and for meteorological and scientific applications: AIRS/Aqua (Aumann et al., 2000, 2003; Hofstadter et al., 2000), OMI/Aura (Levelt et al., 2006), GOME-2A\&B (Munro et al., 2006) and IASI-A\&B (Clerbaux et al., 2009; Hilton et al., 2012). All SACS data retrievals are available in NRT (which means as soon as the data process allows retrieving $\mathrm{SO}_{2}$ and ash observations). Figure 1 shows the different sounders that SACS currently uses and their local overpass time. It shows the advantage of combining multiple sensors which have different overpass times in a single system as it allows the reliable and timely monitoring of volcanic plumes on a global scale.

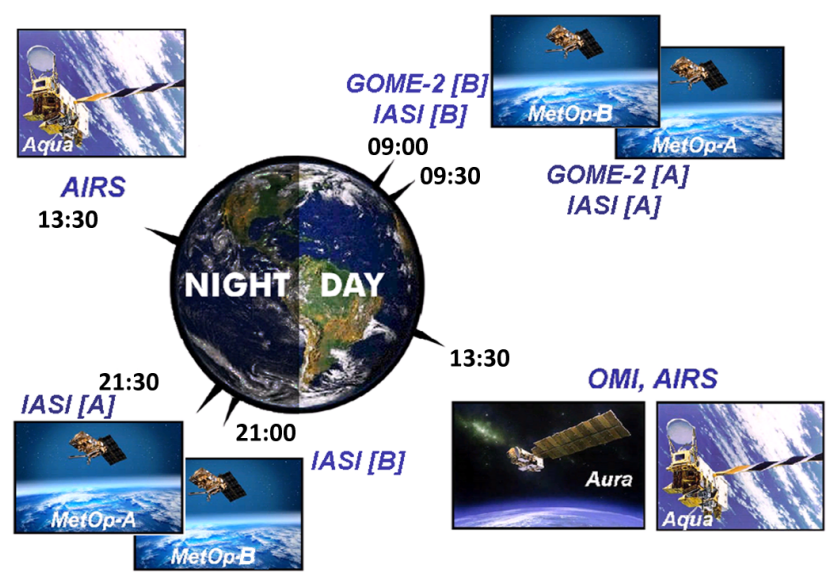

Fig. 1. Illustration of the satellite equatorial overpasses (solar local time).

Note that until April 2012, the NRT SACS system also used data from the SCanning Imaging Absorption spectroMeter for Atmospheric CHartographY (SCIAMACHY) on-board the ENVIronmental SATellite (ENVISAT; see Bovensmann et al., 1999), for which archive data can still be consulted. Table 1 presents a summary of the SACS products and their main characteristics: satellite platform, data type and availability, equatorial local overpass time, spatial resolution, retrieved quantity, data provider, units, delays of retrievals, swath widths, and global coverage. The size of the footprint of each instrument (resolution in $\mathrm{km}^{2}$ ) is an approximate value at nadir. Note that since mid-July 2013, the swath width of GOME-2A has been divided by two (from $1920 \mathrm{~km}$ to $960 \mathrm{~km}$ ), but it still allows a full daily coverage by combining GOME-2A and GOME-2B instruments. A description of the different data products used in the SACS system is given in Sect. 3.

A notification system has been set up to warn people (by email) in case of exceptional concentrations of ash and $\mathrm{SO}_{2}$, pointing them to a web page with relevant information on the location of the plume. Users also have the possibility to consult the notification service, which compiles notifications of ongoing or past eruptive events. Data archives contain the observations starting from September 2002 for AIRS, from January 2004 until April 2012 for SCIAMACHY, from September 2004 for OMI, from January 2007 for GOME-2A, from December 2012 for GOME-2B, from October 2007 for IASIA and from January 2013 for IASI-B.

\section{Description of satellite data products used by SACS}

SACS provides complementary information both on $\mathrm{SO}_{2}$ and aerosol/ash in NRT. The satellite detection of $\mathrm{SO}_{2}$ is straightforward and when $\mathrm{SO}_{2}$ is present in the free troposphere to lower stratosphere, it is (most of the time) a good indicator of volcanic activity. Although $\mathrm{SO}_{2}$ is often a good proxy 
for volcanic ash plumes (Thomas and Prata, 2011), not all eruptions are accompanied by detectable amounts of $\mathrm{SO}_{2}$, and even then it is not uncommon for ash and $\mathrm{SO}_{2}$ to follow different trajectories because of differences in injection altitudes.

Unfortunately, the detection of volcanic ash is far from straightforward, especially for dispersed plumes. Most of the current satellite algorithms use differential absorption by ash between two channels, which can yield false detection in the presence of absorbing aerosols other than ash (e.g. desert dust). However, it has been shown recently by Clarisse et al. (2013a) that it is possible to discriminate the absorption signatures of ash from other types of absorbing aerosols using hyperspectral thermal infrared sensors. In SACS, we have implemented such an algorithm to selectively detect ash for AIRS, IASI-A and IASI-B .

In this section, we briefly present the different products from the seven instruments listed in Table 1 and their main features and limitations. Then, Sect. 4 describes how the SACS system presently uses the satellite data products to trigger and issue notifications for $\mathrm{SO}_{2}$ and ash.

\section{1 $\mathrm{SO}_{2}$ column retrievals from $\mathrm{UV}$-visible sensors (SCIAMACHY, OMI, GOME-2)}

The SCIAMACHY, GOME-2A, GOME-2B and OMI instruments are UV-visible spectrometers measuring solar light backscattered by the atmosphere or reflected by the Earth (and hence can only measure during daytime). The observations are done in nadir-viewing geometry, except for SCIAMACHY, which has alternating viewing modes in nadir and limb (not used here). Once a day, a direct measurement of the solar irradiance spectrum is also acquired. All four instruments have spectral channels covering the UV wavelength range $(240-400 \mathrm{~nm})$, where $\mathrm{SO}_{2}$ has strong and distinctive absorption bands. The spectral resolution in the UV range is $0.2-0.6 \mathrm{~nm}$.

The retrieved quantity from the four algorithms is the so-called $\mathrm{SO}_{2}$ vertical column density (VCD). It represents the $\mathrm{SO}_{2}$ concentration integrated along the vertical axis and is generally expressed in Dobson units $\left(1 \mathrm{DU}=2.69 \times 10^{16} \mathrm{~mol} \mathrm{~cm}^{-2}\right)$. The $\mathrm{SO}_{2}$ retrievals of SCIAMACHY (Van Geffen et al., 2007, 2008) and GOME-2A\&B (Rix et al., 2009, 2012) use a differential optical absorption spectroscopy technique (DOAS; Platt and Stutz, 2008) where all measurements in a wavelength ranging from 315 to $326 \mathrm{~nm}$ are fitted to laboratory absorption data of $\mathrm{SO}_{2}$ (and other atmospheric gases) to yield the $\mathrm{SO}_{2}$ slant column, i.e. the $\mathrm{SO}_{2}$ concentration integrated along the mean optical light path in the atmosphere. The OMI $\mathrm{SO}_{2}$ retrieval is slightly different from SCIAMACHY and GOME-2A\&B in that it uses only a small number of wavelengths (between 310 and $345 \mathrm{~nm}$ ) in and outside the $\mathrm{SO}_{2}$ band, following the linear fit algorithm (Yang et al., 2007), and it does not retrieve an $\mathrm{SO}_{2}$ slant column as an intermediate step. Note that for all instru- ments, several background and offset corrections are generally applied to ensure geophysical consistency of the data.

The $\mathrm{SO}_{2}$ vertical column is obtained using radiative transfer calculations that account for important parameters influencing the UV light path in the atmosphere: solar zenith angle, viewing angles, clouds, atmospheric absorption and scattering and surface albedo. As the measurement sensitivity strongly depends on the altitude at which $\mathrm{SO}_{2}$ resides and because we have no knowledge what this altitude is prior to the measurement, the $\mathrm{SO}_{2}$ vertical column estimation is provided on three hypothetical atmospheric layers representative of different scenarios of emissions: planetary boundary layer (typically the first $\mathrm{km}$ above the surface), upper troposphere $(\sim 6 \mathrm{~km})$ and lower stratosphere $(\sim 15 \mathrm{~km})$. The $\mathrm{SO}_{2}$ images displayed in SACS all use the data assuming lower stratospheric plumes.

The $\mathrm{SO}_{2}$ algorithms from OMI, SCIAMACHY and GOME-2A are able to detect similar $\mathrm{SO}_{2}$ patterns for modest and strong eruptions. Figure 2 shows that the measurements $\left(\mathrm{SO}_{2}\right.$ VCD images from SCIAMACHY, GOME-2A and OMI for an eruption of Kilauea Volcano in Hawaii, 17 May 2008) are able to consistently observe small (and low) $\mathrm{SO}_{2}$ plumes. Despite the different overpass times, we can see a very good spatial correspondence between the three instruments regarding the location of the plume. To compare the $\mathrm{SO}_{2}$ VCDs, a fixed latitude of $19.4^{\circ} \mathrm{N}$ has been chosen for the three instruments, and the measurements have been plotted as a function of longitude (Fig. 2d). A fairly good agreement between the VCD values is found, especially taking into account the fact the $\mathrm{SO}_{2}$ plume is moving westward. This example shows and confirms that $\mathrm{SO}_{2} \mathrm{VCD}$ measurements from UV-visible instruments allow a good estimation and monitoring of volcanic emissions even for such a small eruption (the highest $\mathrm{SO}_{2} \mathrm{VCD}$ is $5.2 \mathrm{DU}$ as recorded by GOME- 2 on this day). Note that the operational cloudcover fraction products for all UV-visible instruments are also available on the SACS web page as additional information. Note that the measurement times are indicated in UTC on all SACS images.

\section{2 $\mathrm{SO}_{2}$ index retrievals from thermal IR sensors (IASI and AIRS)}

The IASI instrument (on-board MetOp-A \& MetOp-B) is a Fourier transform spectrometer. The spectral coverage is from $645 \mathrm{~cm}^{-1}$ to $2760 \mathrm{~cm}^{-1}$ (with no gaps) with a spectral resolution of $0.5 \mathrm{~cm}^{-1}$ (apodised) and a spectral sampling of $0.25 \mathrm{~cm}^{-1}$. The AIRS instrument is an echelle grating spectrometer covering the range between 650 and $2665 \mathrm{~cm}^{-1}$ (with gaps) and a spectral resolution of $0.5-2 \mathrm{~cm}^{-1}$. The instruments operate in a nadir view with typical footprints (circular to elliptical depending on the position on the swath) of 12 and $15 \mathrm{~km}$ diameters (at nadir) for IASI and AIRS respectively. Both sensors measure the spectrum of the outgoing 
Table 1. List of data products available from SACS.

\begin{tabular}{|c|c|c|c|c|c|c|c|c|c|c|}
\hline Instruments & $\begin{array}{l}\text { Data } \\
\text { type }\end{array}$ & $\begin{array}{l}\text { Overpass } \\
\text { time }\end{array}$ & $\begin{array}{l}\text { Data } \\
\text { availability }\end{array}$ & $\begin{array}{l}\text { Resolution } \\
\left(\mathrm{km}^{2}\right)\end{array}$ & $\begin{array}{l}\text { Swath } \\
(\mathrm{km})\end{array}$ & $\begin{array}{l}\text { Global } \\
\text { coverage } \\
\text { (hour) }\end{array}$ & $\begin{array}{l}\text { Data } \\
\text { products }\end{array}$ & Participants & Units & Delay \\
\hline $\begin{array}{l}\text { SCIAMACHY } \\
(E N V I S A T)\end{array}$ & UV/visible & $10: 00$ & 2004/04-2012/04 & $30 \times 60$ & 960 & 96 & $\begin{array}{l}\mathrm{SO}_{2} \text { vertical columns } \\
\text { absorbing aerosol index }\end{array}$ & $\begin{array}{l}\text { BIRA } \\
\text { KNMI }\end{array}$ & $\begin{array}{l}\text { DU } \\
-\end{array}$ & $2-3 h$ \\
\hline $\begin{array}{l}\text { OMI } \\
(\text { Aura })\end{array}$ & UV/visible & $13: 30$ & 2004/09-present & $13 \times 24$ & 2600 & 24 & $\begin{array}{l}\mathrm{SO}_{2} \text { vertical columns } \\
\text { absorbing aerosol index }\end{array}$ & $\begin{array}{l}\text { NASA/ } \\
\text { KNMI/FMI } \\
\text { KNMI }\end{array}$ & $\begin{array}{l}\text { DU } \\
-\end{array}$ & $\begin{array}{l}2-3 \mathrm{~h} \\
\left(\mathrm{EU}: 45^{\prime}\right) \\
2-3 \mathrm{~h}\end{array}$ \\
\hline $\begin{array}{l}\text { GOME-2 } \\
(\text { MetOp-A) }\end{array}$ & UV/visible & 09:30 & $\begin{array}{l}\text { 2007/01-2013/07 } \\
\text { 2013/07-present }\end{array}$ & $\begin{array}{l}40 \times 80 \\
40 \times 40\end{array}$ & $\begin{array}{l}1920 \\
960\end{array}$ & $\begin{array}{l}24 \\
48\end{array}$ & $\begin{array}{l}\mathrm{SO}_{2} \text { vertical columns } \\
\mathrm{SO}_{2} \text { plume height } \\
\text { absorbing aerosol index }\end{array}$ & $\begin{array}{l}\text { DLR } \\
\text { BIRA } \\
\text { KNMI }\end{array}$ & $\begin{array}{l}\text { DU } \\
\mathrm{km} \\
-\end{array}$ & $\begin{array}{l}1-2 \mathrm{~h} \\
\text { off-line } \\
2-3 \mathrm{~h}\end{array}$ \\
\hline $\begin{array}{l}\text { GOME-2 } \\
(\text { MetOp-B) }\end{array}$ & UV/visible & 09:00 & 2012/12-present & $40 \times 80$ & 1920 & 24 & $\begin{array}{l}\mathrm{SO}_{2} \text { vertical columns } \\
\mathrm{SO}_{2} \text { plume height } \\
\text { absorbing aerosol index }\end{array}$ & $\begin{array}{l}\text { DLR } \\
\text { BIRA } \\
\text { KNMI }\end{array}$ & $\begin{array}{l}\mathrm{DU} \\
\mathrm{km} \\
-\end{array}$ & $\begin{array}{l}1-2 \mathrm{~h} \\
\text { off-line } \\
2-3 \mathrm{~h}\end{array}$ \\
\hline $\begin{array}{l}\text { IASI } \\
(\text { MetOp-A) }\end{array}$ & infrared & $\begin{array}{l}09: 30 \\
21: 30\end{array}$ & 2007/10-present & $12 \times 12$ & 2200 & 12 & $\begin{array}{l}\mathrm{SO}_{2} \text { index (and columns) } \\
\text { ash indicator }\end{array}$ & $\begin{array}{l}\text { ULB } \\
\text { ULB }\end{array}$ & $\begin{array}{l}\mathrm{K}(\mathrm{DU}) \\
-\end{array}$ & $\begin{array}{l}1-2 \mathrm{~h} \\
1-2 \mathrm{~h}\end{array}$ \\
\hline $\begin{array}{l}\text { IASI } \\
(M e t O p-B)\end{array}$ & infrared & $\begin{array}{l}09: 00 \\
21: 00\end{array}$ & 2013/01-present & $12 \times 12$ & 2200 & 12 & $\begin{array}{l}\mathrm{SO}_{2} \text { index (and columns) } \\
\text { ash indicator }\end{array}$ & $\begin{array}{l}\text { ULB } \\
\text { ULB }\end{array}$ & K (DU) & $\begin{array}{l}1-2 \mathrm{~h} \\
1-2 \mathrm{~h}\end{array}$ \\
\hline $\begin{array}{l}\text { AIRS } \\
(\text { Aqua })\end{array}$ & infrared & $\begin{array}{l}01: 30 \\
13: 30\end{array}$ & 2002/09-present & $15 \times 15$ & 1650 & 12 & $\begin{array}{l}\mathrm{SO}_{2} \text { vertical columns } \\
\text { ash indicator }\end{array}$ & $\begin{array}{l}\text { NILU } \\
\text { ULB }\end{array}$ & $\begin{array}{l}\text { DU } \\
-\end{array}$ & $\begin{array}{l}1-2 \mathrm{~h} \\
1-2 \mathrm{~h}\end{array}$ \\
\hline
\end{tabular}
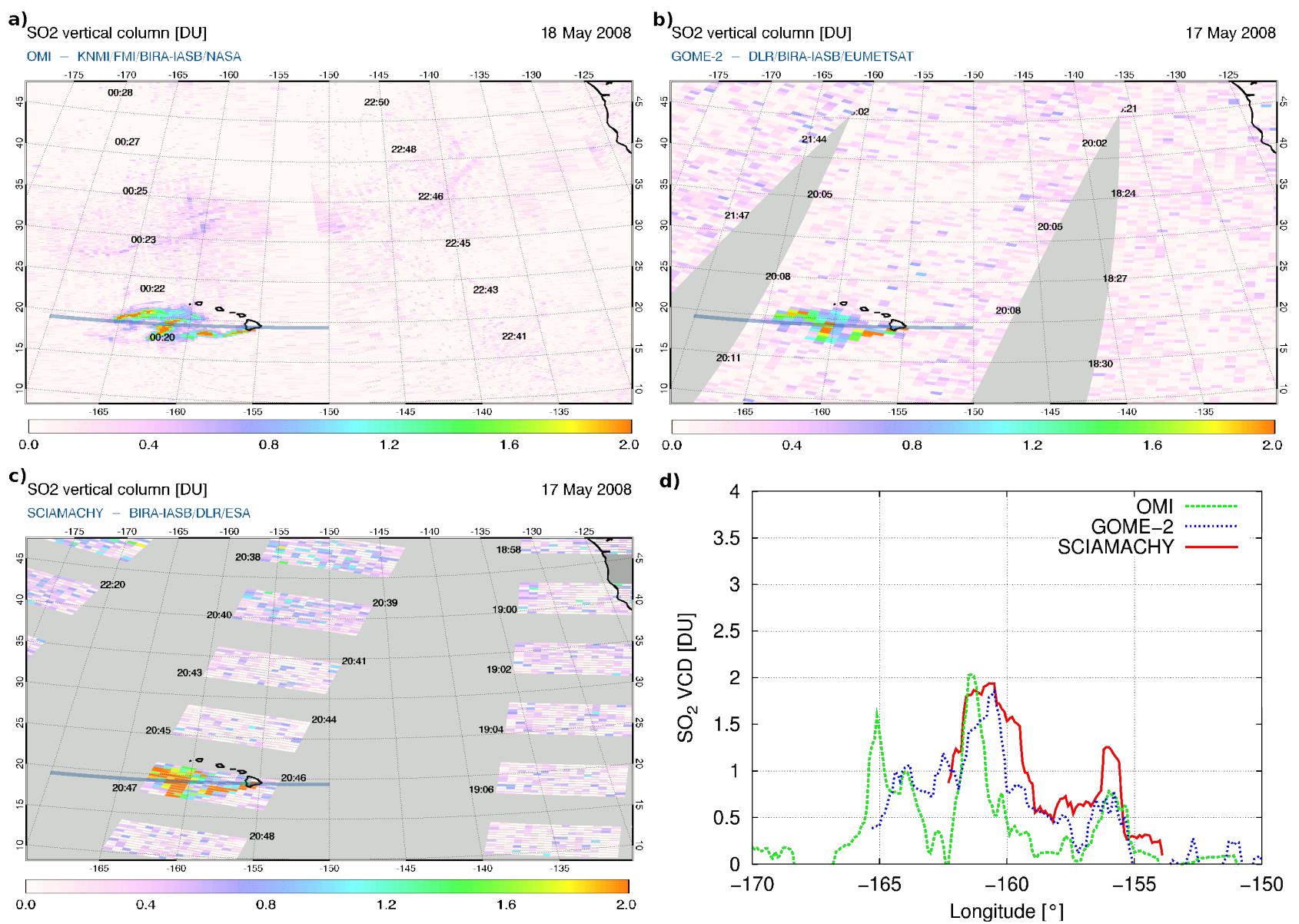

Fig. 2. $\mathrm{SO}_{2}$ VCD images by (a) OMI, (b) GOME-2A and (c) SCIAMACHY. The lower right plot (d) shows the $\mathrm{SO}_{2}$ VCDs for a fixed latitude of $19.4^{\circ} \mathrm{N}$ (blue line in the SO2 images) as a function of longitude during an eruption of Kilauea Volcano $\left(155.29^{\circ} \mathrm{W}, 19.42^{\circ} \mathrm{N}\right)$, 17-18 May 2008. 
thermal radiation emitted by the Earth-atmosphere system (and hence can operate during both day and night).

Both IR instruments cover the strong $\nu_{3}$ (asymmetric stretch) $\mathrm{SO}_{2}$ absorption band around $1362 \mathrm{~cm}^{-1}$. For AIRS, three wave numbers are used $\left(1395 \mathrm{~cm}^{-1}, 1327 \mathrm{~cm}^{-1}\right.$ and $1328 \mathrm{~cm}^{-1}$ ), while the IASI algorithm is based on measurements around $1408 \mathrm{~cm}^{-1}, 1372 \mathrm{~cm}^{-1}$ and $1385 \mathrm{~cm}^{-1}$. The AIRS L1 data are provided in near real time by NASA's Earth Observing System Data and Information System (EOSDIS, https://urs.eosdis.nasa.gov), and the $\mathrm{SO}_{2}$ retrievals are processed by BIRA-IASB using the algorithm from NILU. The retrieval scheme of AIRS is a two-step process with a first step to identify pixels that contain $\mathrm{SO}_{2}$ and a second step to adjust the amount of $\mathrm{SO}_{2}$ based on off-line radiative transfer calculations (see details in Prata and Bernardo, 2007). The retrievals from IASI-A\&B $\mathrm{SO}_{2}$ are provided in NRT by the ULB (http://cpm-ws4.ulb.ac.be/Alerts). The IASI $\mathrm{SO}_{2}$ algorithm (see details in Clarisse et al., 2012) also involves the conversion of the measured signal into an $\mathrm{SO}_{2}$ vertical column by making use of a large look-up table and EUMETSAT operational pressure, temperature and humidity profiles. These are only available for data with L2 information. To ensure a maximum amount of IASI data, only the brightness temperature difference index is used in the NRT treatment of SACS. Figure 3 shows IASI-A and AIRS $\mathrm{SO}_{2}$ images from SACS after the beginning of the eruption of the Nabro Volcano (Eritrea). IASI was the first instrument to observe the $\mathrm{SO}_{2}$ plume at 06:25 and 08:05 UTC (for two consecutive orbits) on 13 June 2011. Nevertheless, these observations did not cover the full plume. At 10:50, a full coverage of the plume was possible by combining IASI with AIRS measurements. This illustrates the benefit of our multi-sensor approach. As a side note, the delay time for receiving the data was about $1 \mathrm{~h} 50 \mathrm{~min}$ and $1 \mathrm{~h} 30 \mathrm{~min}$ for IASI and AIRS respectively.

\subsection{Absorbing aerosol index retrievals from UV-visible sensors (SCIAMACHY, OMI, GOME-2)}

The absorbing aerosol index (AAI) indicates the presence of elevated absorbing aerosols in the atmosphere. It is often called the residue, the spectral contrast anomaly or simply aerosol index. Because the presence of ash can be the dominant part of the AAI detection, SACS provides these products in near real time. The AAI separates the spectral contrast of two ultraviolet wavelengths caused by absorbing aerosols from that of other effects, including molecular Rayleigh scattering, surface reflection, gaseous absorption and aerosol/cloud scattering (Herman et al., 1997; Torres et al., 1998).

The UV wavelengths used are 340 and $380 \mathrm{~nm}$ for SCIAMACHY and GOME-2A\&B, and 354 and $388 \mathrm{~nm}$ for OMI. Note that AAI retrieval is possible over cloud-covered areas and is performed equally well over ocean and land (except over ice). However, the final AAI products are sensitive to calibration issues and sunglint over the ocean and therefore ad hoc flags are applied. Figure $4 \mathrm{c}$ and $\mathrm{d}$ shows an example of AAI images from the UV-visible sensors GOME-2A and OMI. Ash emitted during the Grímsvötn eruption is clearly identified.

\subsection{Ash index retrieval from the thermal IR sensors (IASI, AIRS)}

Clarisse et al. (2010, 2013a) have demonstrated the potential of hyperspectral thermal infrared sounders to detect volcanic ash with a high sensitivity and differentiate it from other airborne aerosols (including windblown sand). The IASI-A\&B and AIRS ash index products used in SACS are based on a three-step process (see Clarisse et al., 2013a for details). The first step calculates the relative distance (weighted projection) between the measured spectra and fixed ash spectral signatures. Based on the magnitude of these distances, only those observations are kept which are likely to be ash (called ash candidates). The second step finds the subset of observations which are almost certainly ash by imposing very strict criteria based on absolute distance criteria (called high-confidence detections).The third steps considers the spatial context for promoting ash candidates to lowand medium-confidence detections in the neighbourhood of high-confidence detections. The procedure ensures a very low false detection rate (because of step 2), while at the same time identifying as much ash as possible in the neighbourhood of high-confidence detections (because of steps 1 and 3). Therefore, this ash detection provides different levels of confidence. In SACS, four colour codes are adopted. Level 3 (high, in red): in these pixels, ash is almost certainly present (less than $1 \%$ of false alerts). Level 2 (medium, in orange): ash is detected with high confidence; nevertheless, only Level 3 is used to generate a notification. Level 1 (low, in yellow): the observed spectra contain a mineral aerosol signature and are located close to a high-confidence detection. Volcanic ash is therefore likely, even though false detections are common. Level 0 (unknown, in white): in these pixels no ash was detected with the algorithm. Figure 4a presents the AIRS detection of ash at 03:40 UTC on 22 May 2011. Note that IASI was the first instrument on a polar-orbiting satellite able to clearly distinguish ash emitted at the start of the Grímsvötn eruption at 20:45 UTC on 21 May 2011. Figure $4 \mathrm{~b}$ shows the IASI-A ash detection at 10:30 UTC on 22 May. We can see in Fig. $4 c$ and d the displacement of the ash cloud during the next two days (ash detected by AAI retrievals from GOME-2A and OMI). 

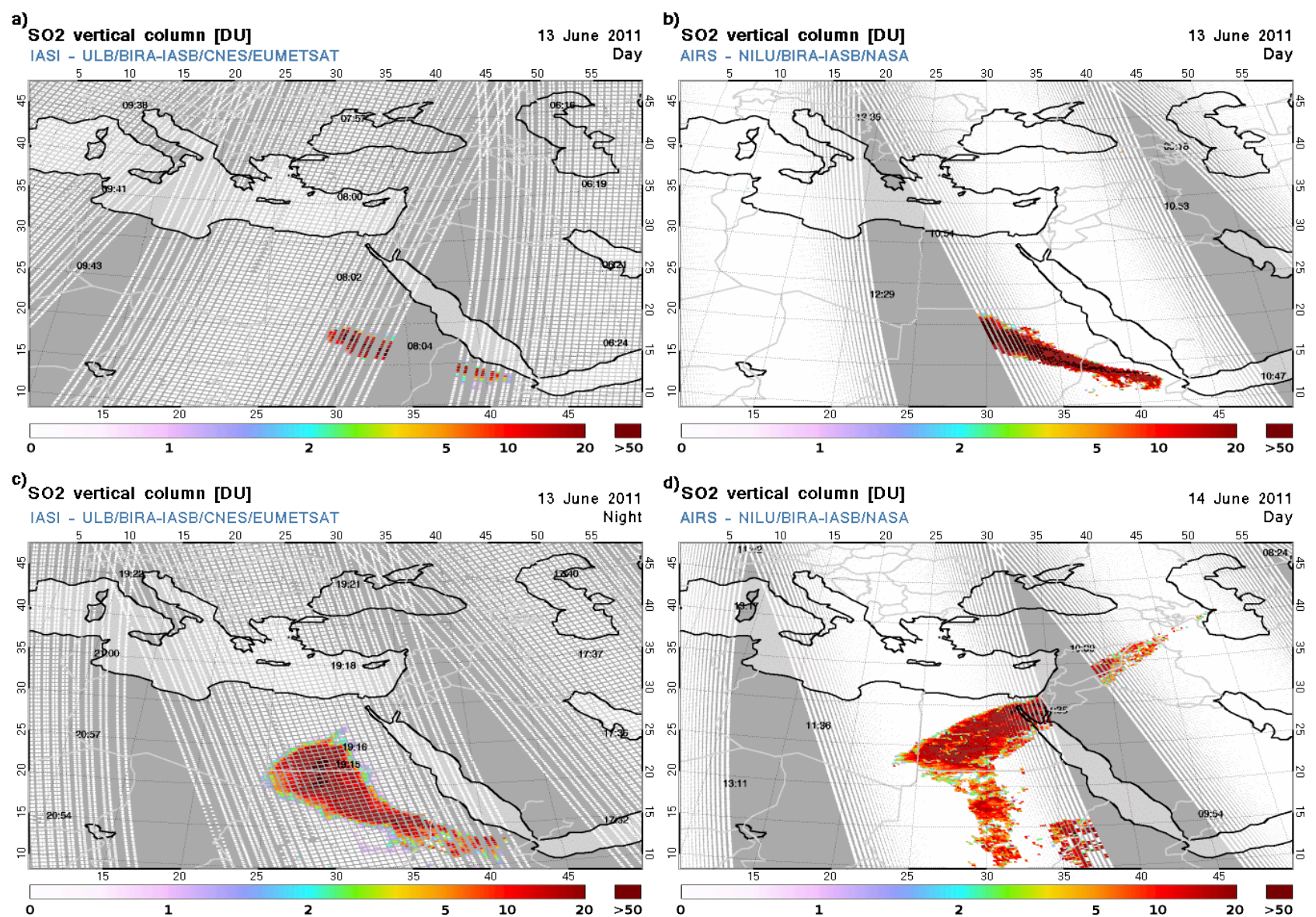

Fig. 3. SACS $\mathrm{SO}_{2}$ vertical column density images from IASI and AIRS for 13 and 14 June 2011 at the beginning of the eruption of Nabro. Note that IASI and AIRS observations are plotted using circles with mean diameters of respectively 12 and $15 \mathrm{~km}$.

Table 2. Geographical coverage of SACS monitoring for October 2012.

\begin{tabular}{|c|c|c|c|c|c|c|c|c|c|c|c|c|c|c|c|c|}
\hline \multirow[b]{3}{*}{ Zone } & \multicolumn{16}{|c|}{ Duration of monitoring } \\
\hline & \multicolumn{2}{|c|}{$1 \mathrm{~h}$} & \multicolumn{2}{|c|}{$2 \mathrm{~h}$} & \multicolumn{2}{|c|}{$3 \mathrm{~h}$} & \multicolumn{2}{|c|}{$4 \mathrm{~h}$} & \multicolumn{2}{|c|}{$6 \mathrm{~h}$} & \multicolumn{2}{|c|}{$8 \mathrm{~h}$} & \multicolumn{2}{|c|}{$12 \mathrm{~h}$} & \multicolumn{2}{|c|}{$24 \mathrm{~h}$} \\
\hline & Pixel & $(\max )$ & Pixel & $(\max )$ & Pixel & $(\max )$ & Pixel & $(\max )$ & Pixel & $(\max )$ & Pixel & $(\max )$ & Pixel & $(\max )$ & Pixel & $(\max )$ \\
\hline A & $14.5 \%$ & (5) & $28.8 \%$ & (5) & $42.5 \%$ & (5) & $55.0 \%$ & (7) & $75.0 \%$ & (8) & $88.5 \%$ & (8) & $98.0 \%$ & (8) & $100 \%$ & (13) \\
\hline B & $15.9 \%$ & (5) & $31.2 \%$ & (5) & $46.0 \%$ & (6) & $59.0 \%$ & (7) & $78.5 \%$ & (8) & $90.9 \%$ & (8) & $98.5 \%$ & (9) & $100 \%$ & (15) \\
\hline $\mathrm{C}$ & $18.8 \%$ & (5) & $36.1 \%$ & (7) & $51.3 \%$ & (8) & $64.8 \%$ & (9) & $84.9 \%$ & (10) & $97.0 \%$ & (10) & $99.7 \%$ & (11) & $100 \%$ & (17) \\
\hline D & $24.7 \%$ & (7) & $44.8 \%$ & (9) & $57.9 \%$ & (11) & $71.0 \%$ & (12) & $90.3 \%$ & (13) & $99.8 \%$ & (14) & $100 \%$ & (15) & $100 \%$ & (23) \\
\hline $\mathrm{E}$ & $31.3 \%$ & (8) & $50.1 \%$ & (10) & $61.9 \%$ & (14) & $72.5 \%$ & (19) & $87.9 \%$ & (22) & $96.0 \%$ & (30) & $99.4 \%$ & (38) & $100 \%$ & (71) \\
\hline $\mathrm{F}$ & $72.5 \%$ & (8) & $94.8 \%$ & (10) & $97.3 \%$ & (14) & $98.8 \%$ & (19) & $100.0 \%$ & (22) & $100 \%$ & (30) & $100 \%$ & (38) & $100 \%$ & (71) \\
\hline World & $31.6 \%$ & (8) & $50.6 \%$ & (10) & $62.3 \%$ & (14) & $72.8 \%$ & (19) & $88.1 \%$ & (22) & $96.1 \%$ & (30) & $99.4 \%$ & (38) & $100 \%$ & (71) \\
\hline
\end{tabular}

\subsection{Limitations of satellite products in detecting volcanic plumes}

\subsection{1 $\mathrm{SO}_{2}$ products}

Because of competing water vapour absorption in the same IR wavelength window as $\mathrm{SO}_{2}$, the vertical sensitivity of IASI and AIRS to $\mathrm{SO}_{2}$ is limited to the atmospheric layers above $3-5 \mathrm{~km}$, depending on the humidity vertical profile. This limitation might seem serious, but in the context of aviation it is actually an advantage as the detection of $\mathrm{SO}_{2}$ by these two sensors means that $\mathrm{SO}_{2}$ is present at altitudes where airplanes spend most of their travel time. This fact combined with four overpasses per day makes the IR sensors a central component of the SACS system. As a complement, the UV sensors are characterised by a relatively good measurement sensitivity for $\mathrm{SO}_{2}$ down to the surface. While this allows monitoring of low-altitude volcanic degassing, it also renders the measurements sensitive to anthropogenic 

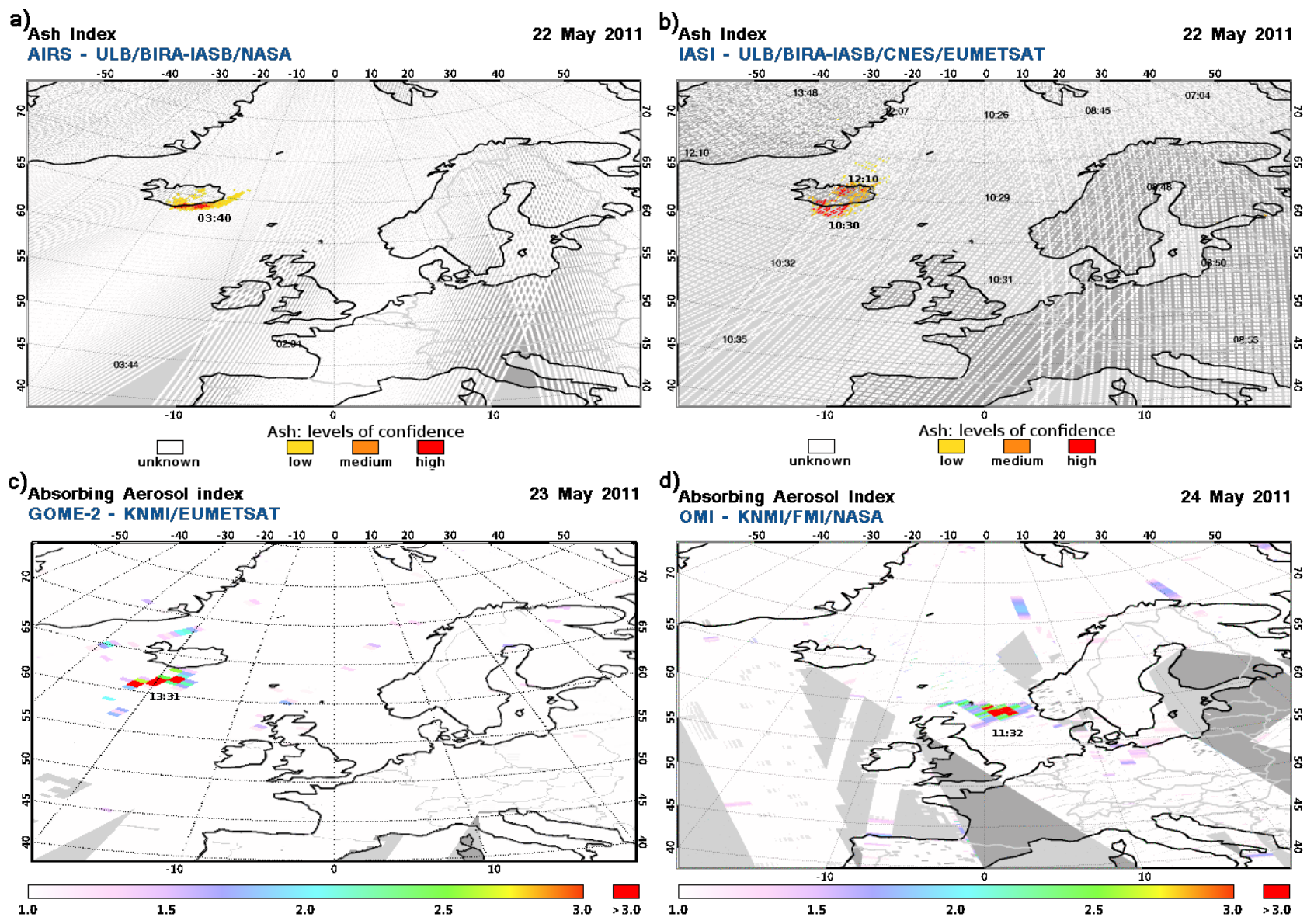

Fig. 4. Ash index from (a) IASI-A and (b) AIRS, and AAI from (c) GOME-2A and (d) OMI during the Grímsvötn eruption on Iceland. Images show the first days of the eruption, which started on the afternoon of 21 May 2011.

emissions. As most of the $\mathrm{SO}_{2}$ pollution hotspots are confined to a limited number of regions (China, South Africa and Siberia), the SACS system can easily be tuned to avoid false notifications there. As a general comment, $\mathrm{SO}_{2}$ retrievals are also affected by clouds and instrumental noise (especially at high solar zenith angles for the UV sensors). The latter generally shows up in the $\mathrm{SO}_{2}$ images and evolves as the instrument degrades over time.

\subsubsection{Aerosol products}

Besides the fact that aerosol products are qualitative products (indexes), measurements from UV-visible sensors are sensitive to all types of absorbing aerosols (desert dust, biomassburning aerosols, volcanic ash) and are therefore not purely selective for ash. However, the combined detection of both elevated aerosol and $\mathrm{SO}_{2}$ is highly selective for the volcanic plume (in fact even more than $\mathrm{SO}_{2}$ detection alone). Note that the ash product of IASI and AIRS sensors yields very few false detections (less than $1 \%$ ). It should be noted that because of the strict conditions of step 2 presented in
Sect. 3.4, low-concentration ash plumes are often not detected in the current implementation.

\subsubsection{Known anomalies impacting the data}

The Earth's dipolar magnetic field is offset by about $500 \mathrm{~km}$ from the rotational axis. As a result of this, the inner Van Allen belt (doughnut-shaped regions of high-energy charged particles) is closer to the Earth's surface on one side than on the other. This region is called the South Atlantic Anomaly (SAA) and it covers a part of South America and the southern Atlantic Ocean: it lies roughly between latitudes $5^{\circ} \mathrm{S}$ and $40^{\circ} \mathrm{S}$, and between longitudes $0^{\circ} \mathrm{W}$ and $80^{\circ} \mathrm{W}$ (the precise strength, shape and size of the SAA varies with the seasons). This dip in the Earth's magnetic field allows charged particles and cosmic rays to penetrate lower into the ionosphere (to $\sim 500 \mathrm{~km}$ of altitude). Low-orbiting satellites, such as Envisat, Aura, MetOp-A and MetOp-B, pass daily through the inner radiation belt in the SAA-region. Upon passing the inner belt, charged particles may impact the detector, causing higher than normal radiance values, which in turn decreases the quality of the measurements, notably in the UV 
Table 3. Key criteria used by the SACS notification system.

\begin{tabular}{|c|c|c|c|c|c|c|}
\hline & Instruments & SCIAMACHY & $\begin{array}{l}\text { GOME-2 } \\
\text { [MetOp-A \& -B] }\end{array}$ & OMI & $\begin{array}{l}\text { IASI } \\
{[\text { MetOp-A \& -B] }}\end{array}$ & AIRS \\
\hline \multirow{8}{*}{$\begin{array}{l}\mathrm{SO}_{2} \\
\text { notification }\end{array}$} & threshold radius & $80 \mathrm{~km}$ & $85 \mathrm{~km}$ & $50 \mathrm{~km}$ & no need & no need \\
\hline & type of observation & VCD & VCD & VCD & DBT & VCD \\
\hline & $\begin{array}{l}\text { threshold value } \\
\text { threshold value }\end{array}$ & $1.8 \mathrm{DU}$ & $1.8 \mathrm{DU}$ & $1.45 \mathrm{DU}$ & $2.9 \mathrm{~K}$ & $3 \mathrm{DU}$ \\
\hline & $\begin{array}{l}\text { proximity volcano } \\
(<300 \mathrm{~km})\end{array}$ & $1.25 \mathrm{DU}$ & $1.45 \mathrm{DU}$ & $1.25 \mathrm{DU}$ & no need & no need \\
\hline & avoid SAA & yes & yes & no need & no need & no need \\
\hline & threshold value & $3.25 \mathrm{DU}$ & $2 \mathrm{DU}$ & no need & no need & no need \\
\hline & avoid pollution & & yes & & no need & no need \\
\hline & threshold value & $3.25 \mathrm{DU}$ & $2 \mathrm{DU}$ & $1.6 \mathrm{DU}$ & no need & no need \\
\hline \multirow{12}{*}{$\begin{array}{l}\text { Ash } \\
\text { notification }\end{array}$} & level of confidence (LOC) & N/A & N/A & N/A & high & high \\
\hline & threshold radius & N/A & N/A & N/A & $2000 \mathrm{~km}$ & $2000 \mathrm{~km}$ \\
\hline & NOP* required & N/A & N/A & N/A & 1 high \& 2 medium & 1 high \& 2 medium \\
\hline & special regions & & & & & \\
\hline & threshold radius & N/A & N/A & N/A & $800-2000 \mathrm{~km}$ & $800-2000 \mathrm{~km}$ \\
\hline & $\mathrm{NOP}^{*}$ required & N/A & N/A & N/A & $\begin{array}{l}1 \text { high \& } 4 \text { to } 99 \\
\text { medium }\end{array}$ & $\begin{array}{l}1 \text { high \& } 4 \text { to } 49 \\
\text { medium }\end{array}$ \\
\hline & $<80 \mathrm{~km}$ from volcanoes & & & & & \\
\hline & threshold radius & N/A & N/A & N/A & $800 \mathrm{~km}$ & $800 \mathrm{~km}$ \\
\hline & $\mathrm{NOP}^{*}$ required & N/A & N/A & N/A & 1 high & 1 high \\
\hline & $<200 \mathrm{~km}$ from volcanoes & & & & & \\
\hline & threshold radius & N/A & N/A & N/A & $800 \mathrm{~km}$ & $800 \mathrm{~km}$ \\
\hline & NOP* required & N/A & N/A & N/A & 1 high \& 1 medium & 1 high \& 1 medium \\
\hline
\end{tabular}

* Number of medium or high LOC pixels in the area in the threshold radius.
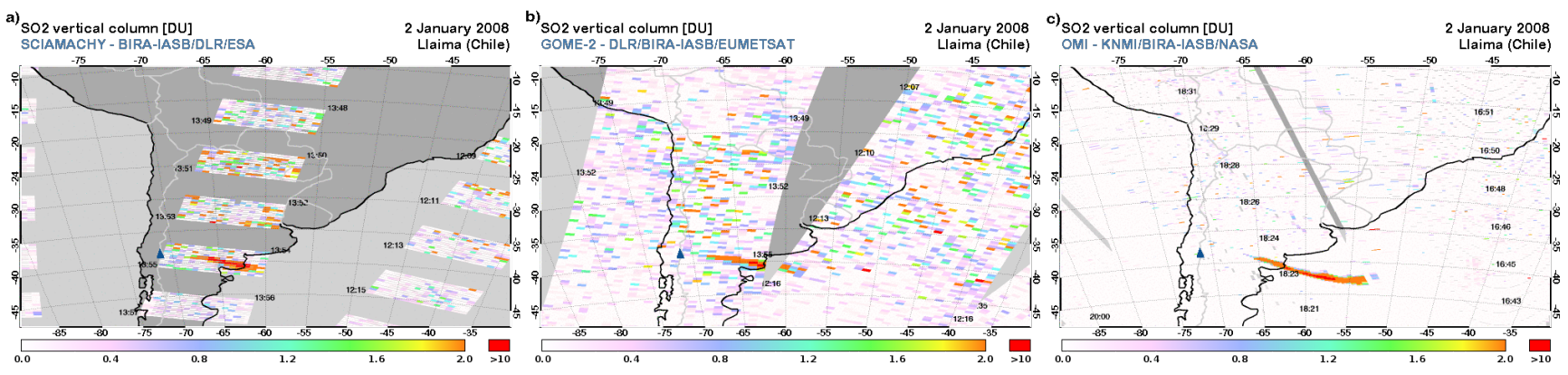

Fig. 5. Example of $\mathrm{SO}_{2}$ VCD from (a) SCIAMACHY, (b) GOME-2A and (c) OMI on 2 January 2008 in the region affected by the SAA. The $\mathrm{SO}_{2}$ plume is related to the eruption of the Llaima Volcano (Chile), marked by a blue triangle in the plots. Artefacts induced by the South Atlantic Anomaly in the $\mathrm{SO}_{2}$ VCD from SCIAMACHY and GOME-2 instruments are visible in these images; OMI is less affected.

wavelength ranges. The SAA affects the $\mathrm{SO}_{2}$ retrievals and results in noise artefacts, as is visible in Fig. 5a and b. Thanks to its design, which gives it better protection to radiation than other sensors, OMI is less affected by the SAA than SCIAMACHY or GOME-2A (as can be seen in Fig. 5c).

The OMI instrument started to suffer from a so-called "row anomaly" on 25 June 2007. This anomaly affects particular viewing direction angles, corresponding to rows on the charge-coupled device (CCD) detector. The row anomaly has increased over time (see www.knmi.nl/omi/research/ product). Currently, the affected rows are not treated in SACS, leading to a reduction in the data coverage. Several off-line schemes to correct for the row anomaly exist (e.g. Yan et al., 2012) but are not implemented yet in the NRT data processing. 


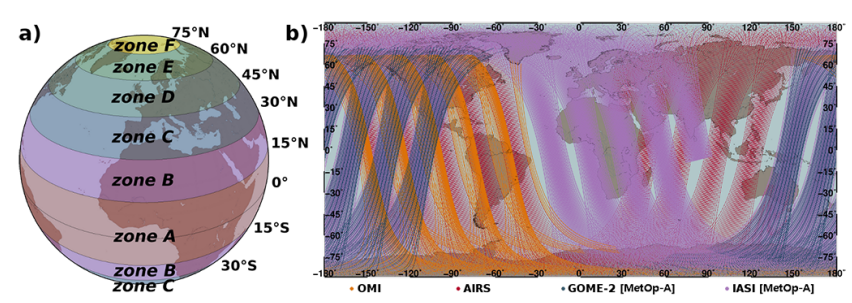

Fig. 6. (a) Geographical zones used in Table 2; (b) $8 \mathrm{~h}$ of monitoring from SACS instruments (example used: 27 October 2012, with four instruments).

\section{Global monitoring of volcanic $\mathrm{SO}_{2}$ and ash emissions}

In this section we present results from the SACS global monitoring system of $\mathrm{SO}_{2}$ and ash emissions and the strategy adopted to warn users of exceptional concentrations.

\subsection{Temporal and spatial sampling}

It is important to know precisely the time and space sampling of the SACS monitoring system. Because of the use of polar-orbiting satellites with different overpass times, some geographical regions are observed more frequently than others. To evaluate the revisiting frequency of SACS, we have defined seven geographical latitude zones (see Fig. 6a) and, based on data of October 2012, we have estimated the percentage of the areas that have been observed at least once by one of the satellite instruments (OMI, GOME-2A, IASI-A and AIRS). The calculation was done for several time intervals (see, e.g., the coverage of the Earth by SACS after $8 \mathrm{~h}$ of monitoring in Fig. $6 \mathrm{~b}$ ). Table 2 presents the results for the different zones and time durations. A set of two parameters has been evaluated: Pixel is the percentage of the region of interest sampled by the SACS system, and max is the maximum number of overpasses. From Table 2, it can be seen, that with four instruments, SACS monitors any location in the world in near real time within a $24 \mathrm{~h}$ interval. The percentage value drops to $99.5,95,90,75,60,50$ and $30 \%$ for periods of $12,8,6,4,3,2$ and $1 \mathrm{~h}$ respectively.

Also apparent is the higher sampling rate for high-latitude regions due to overlapping orbits. This is particularly interesting for Icelandic volcanoes (zone E), which will be sampled, e.g., every $2 \mathrm{~h} 50 \%$ of the time (see Table 2). Note that the geographical coverage of D-E-F zones depends on the day of the year. For example, in December, the coverage of Iceland is less good (due to the solar zenith angle (SZA) limit for UV-visible instruments). Nevertheless, because the IR sensors are not affected by the SZA limit criteria (day and night measurements), the coverage of the high-latitude regions always takes advantage of overlapping orbits over North and South Poles.

\subsection{SACS strategy for volcanic $\mathrm{SO}_{2}$ and ash notifications}

Here, we detail the implementation of the global multi-sensor notification system for $\mathrm{SO}_{2}$ and ash. It requires two steps: (1) proper establishment of warning criteria for the different sensors; (2) combining the information from the sensors in one system. Particular attention is given to the avoidance of false notifications (due to noise or retrieval failures) or overly frequent/redundant notifications (caused by highly dispersed plumes).

\subsubsection{Criteria for $\mathrm{SO}_{2}$ and ash notifications}

The criteria for the detection of exceptional $\mathrm{SO}_{2}$ concentrations from the seven instruments has been derived from the analysis of historical results (see Table 1 for the data periods considered). Each instrument and retrieval method has different characteristics; therefore, for each data source different notification threshold values have been established. Note that, even though it no longer provides data, SCIAMACHY is included here because it has been used in the past and notifications based on its data are in the SACS archive.

The detection of exceptional ash concentrations is not applicable (N/A) for the UV-visible instruments. For the three thermal infrared sensors, the criteria of this detection are generally straightforward using the three-step approach specified in Sect. 3.4, with a dependency on the high level of confidence (LOC); see Clarisse et al., 2013a. If one pixel with a high LOC and two with a medium LOC are identified, a notification is issued. Nevertheless, for some desert regions (i.e. Arizona/USA, the north of Argentina, the centre of Australia, Mongolia) and for some cold regions (i.e. close to the lakes in the centre of Canada, the east coast of Greenland, the North and South Pole, New Zealand) stricter criteria were applied to avoid more false detections. Two criteria are considered. The first one is the threshold radius (in $\mathrm{km}$ ) applied to evaluate the surrounding pixels. Generally the threshold radius used is $2000 \mathrm{~km}$ (see Table 3 ). The second criterion is the number of pixels with a medium or a high LOC in the area defined by the threshold radius (noted as NOP in Table 3 ). Generally this NOP is $1+2$ (one high and two medium LOC). But to avoid false ash detection in some regions, the threshold radius is decreased to $800 \mathrm{~km}$, and the NOP considered increases from 5 pixels (for the whole North and South Pole) up to 100 pixels for the most constrained region (i.e. north Argentina and some of the regions of the South Pole that correspond to SACS regions 506 and 507; see Fig. 9). Note that if one high LOC pixel is detected in a region with no strict criteria, this will automatically issue a notification. To facilitate the establishment of notification close to a volcano (even in a region with strict criteria), the specific threshold radius and NOP are considered (see Table 3; proximity to volcano of 80 or $200 \mathrm{~km}$ ). For regions with very strict criteria, note that, in comparison to AIRS, the strongest NOP criteria are 
a)

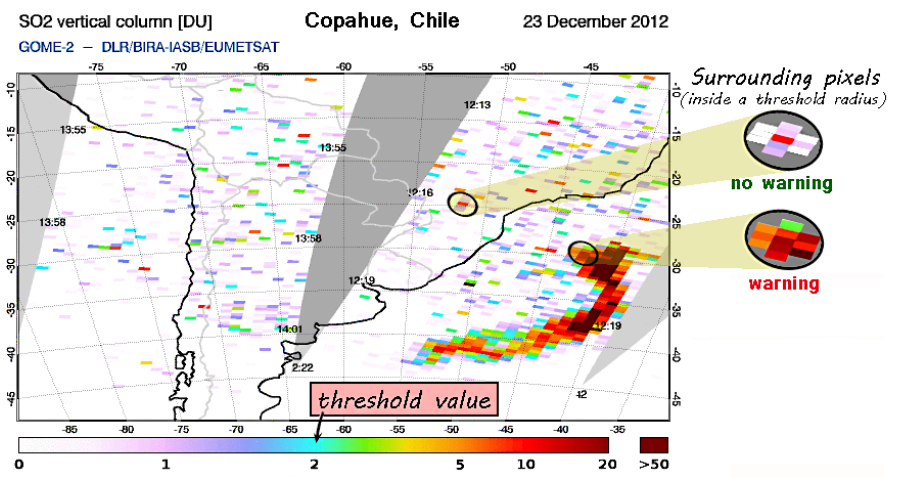

b)

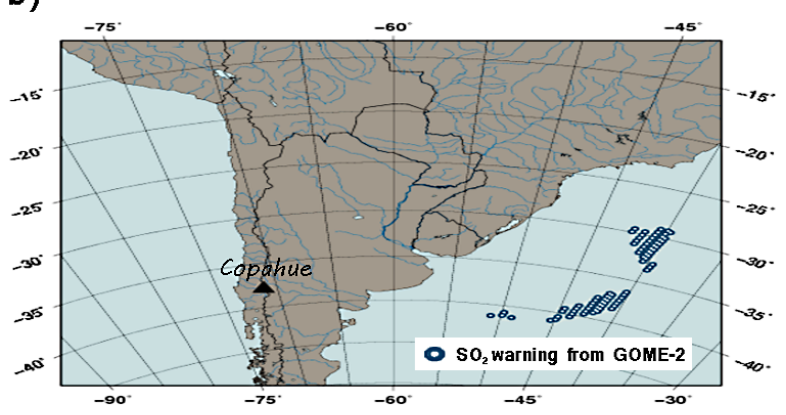

Fig. 7. Eruption of the Copahue Volcano on 23 December 2012. (a) $\mathrm{SO}_{2}$ vertical column density from GOME-2A. A zoom for two pixels above the "threshold value" is shown with the warnings issued. The black ellipse represents the area defined by the "threshold radius" considered in the SACS warning system (see Table 3). (b) Locations of $\mathrm{SO}_{2}$ warnings pixels.

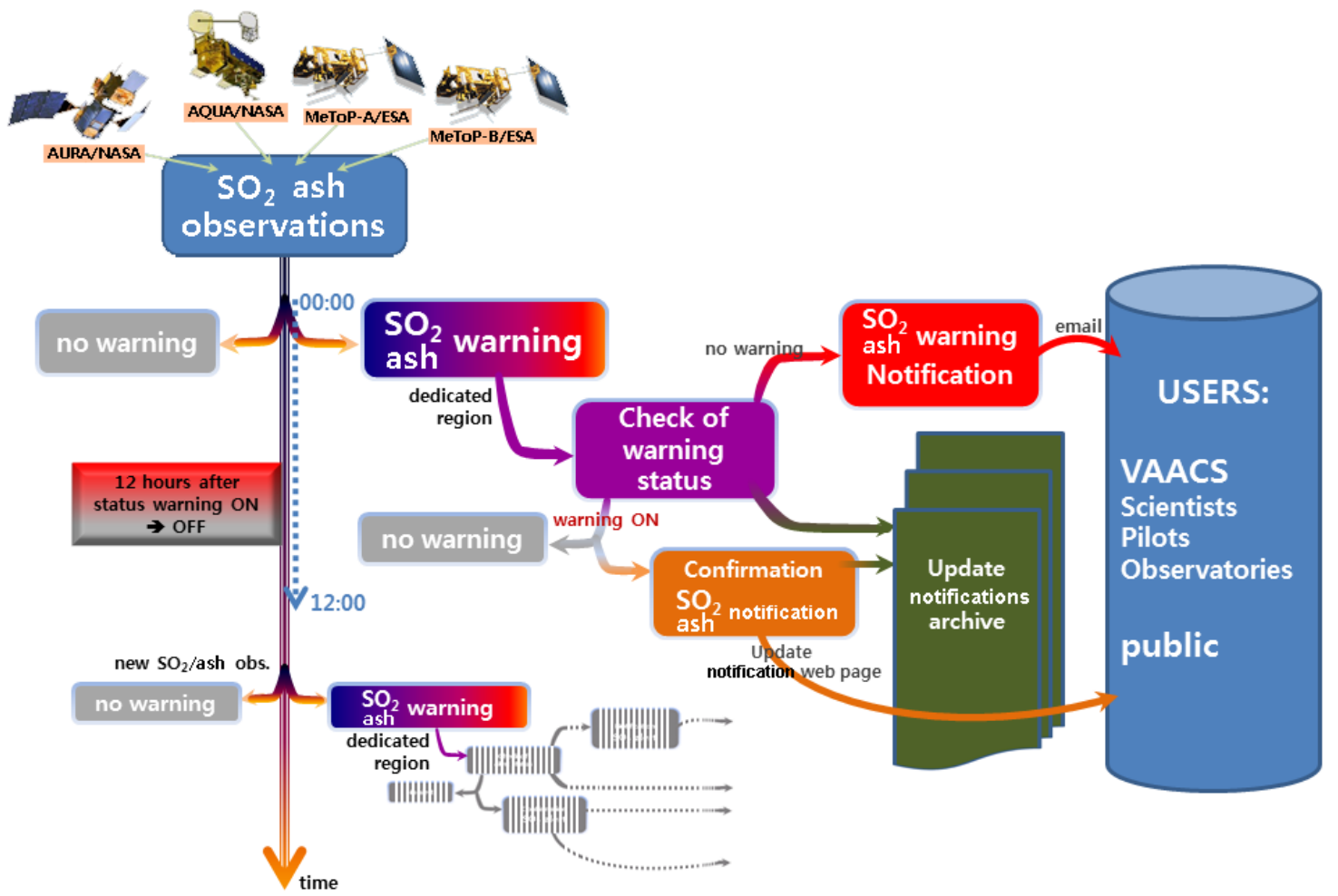

Fig. 8. Overview of the SACS notification system.

required for IASI to avoid false detection (specially in the South Pole regions).

\section{$\mathrm{SO}_{2}$ notification from UV-visible sensors}

The instrumental noise on the UV-visible data is a limitation and can lead to false notifications. For this reason, a first selection criterion is based on the maximum observed value for the $\mathrm{SO}_{2}$ column which must exceed the relevant threshold. An additional criterion is based on the neighbouring pixels (inside a threshold radius; see Table 3 and Fig. 7), for which the observed $\mathrm{SO}_{2}$ column for more than half of the observations must also exceed the threshold value. A notification is generated only when both criteria are fulfilled. An illustration is given in Fig. 7 for GOME-2 for an $\mathrm{SO}_{2}$ plume from the Copahue Volcano (23 December 2012).

Another limitation of UV-visible sensors comes from the South Atlantic Anomaly (see Sect. 3.5.3). To avoid false notifications in this region, a stricter threshold value is considered (see Table 3). Note also that special settings are used for $\mathrm{SO}_{2}$ plumes from small eruptions and degassing, in that the 


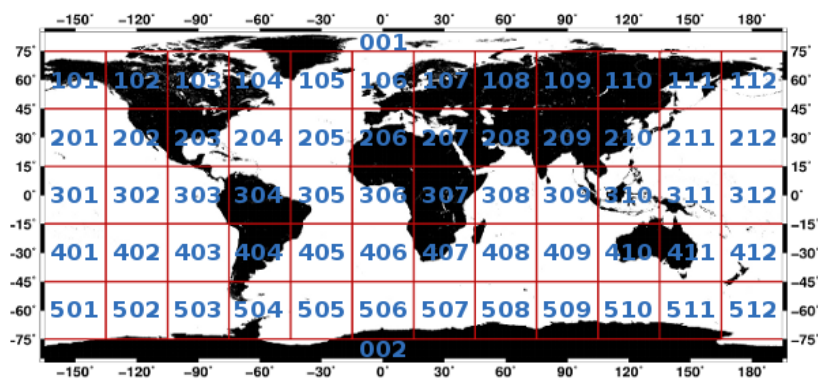

Fig. 9. Predefined world regions used by the SACS notification system and the monitoring service.

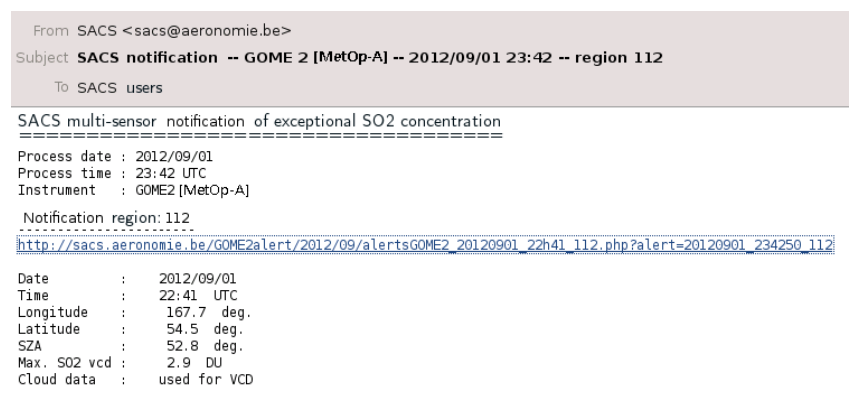

Fig. 10. Example of an email notification sent to users in the case of an exceptional $\mathrm{SO}_{2}$ concentration detected.

system considers lower threshold values for measurements close to a given volcano (distances less than $300 \mathrm{~km}$ ). Finally, one more limitation of UV-visible sensors is that they are sensitive to anthropogenic $\mathrm{SO}_{2}$ emissions. To avoid false notifications, stricter criteria are used for some specific areas (west China, central north Russia and South Africa).

\section{$\mathrm{SO}_{2}$ and ash notifications from thermal IR sensors}

IASI-A\&B and AIRS are much less or not at all affected by instrumental noise, the SAA or pollution. For $\mathrm{SO}_{2}$ detection from IASI, rather than considering threshold values based on VCD, the criteria are applied directly to the measured difference of brightness temperatures (called DBT and expressed in Kelvin $(\mathrm{K})$ ), and are therefore straightforward. The threshold values (DBT and VCD) used are given in Table 3 for, respectively, IASI-A\&B and AIRS, and they produce almost no false notifications. For ash detections from IASI-A\&B and AIRS, as soon as a high level of confidence is obtained (Clarisse et al., 2013a), a notification is generated by the SACS system. Nevertheless, some regions need stricter criteria (i.e. the number of pixels with a medium or high level of confidence in the surrounding region defined by a threshold radius, as mentioned in Table 3 ).

\subsubsection{SACS multi-sensor $\mathrm{SO}_{2}$ and ash-warning system}

The $\mathrm{SO}_{2}$ and ash-warning service relies on pre-defined geographical regions. SACS sends a notification to users as soon as a new volcanic plume is detected. If, within a period of $12 \mathrm{~h}$, a plume is detected again in the same region, no new notification is generated (to avoid sending redundant information). An illustration of the SACS multi-sensors warning system is presented in Fig. 8. The different parts are described in more detail below.

\section{$\mathrm{SO}_{2}$ and ash notifications for a dedicated region}

As soon as SACS harvests new $\mathrm{SO}_{2}$ and ash observations (from one of the instruments), the first step is the analysis of the data using the criteria defined in Sect. 4.2.1. After a volcanic eruption, there are potentially multiple warnings generated by the system. For this reason, it has been decided to consider a set of world regions of $30^{\circ}$ by $30^{\circ}$ plus two polar regions polewards of $75^{\circ}$ in latitude. Figure 9 shows the locations (and associated name/number) of the 62 regions of the SACS system. Note that the same regions are used in the near-real-time monitoring and archive services to display the $\mathrm{SO}_{2}$ and ash images. As soon as a notification is issued, the related region is flagged "ON".

\section{Checking of the warning status}

The second step is to check the "warning status" of this region. If there is no ongoing notification for this region (meaning no notification for $12 \mathrm{~h}$ ), the warning status may possibly change to ON. The system compares the time of observations with the processing time. If the delay is less than $8 \mathrm{~h}$, the notification is issued. This set-up enables the provision of timely information to the users and also avoids issuing too many notifications (maximum of one notification per region and per $12 \mathrm{~h}$ ).

\section{Email notification}

Important information related to the warning is gathered into a notification sent by email to users who subscribed to SACS (http://sacs.aeronomie.be/alert/subscribe.php). The email notification (see also the example shown in Fig. 10) contains the following: the time of the notification and the instrument, the region number, the date and time of observations (UTC), some details about the processing, and a link to a dedicated web page generated by the system. For an $\mathrm{SO}_{2}$ notification, coordinates of the maximum signal are specified with a flag indicating whether a cloud correction has been applied or not, and the solar zenith angle is specified. For an ash notification, the number of pixels with a high, medium and low level of confidence is given. 


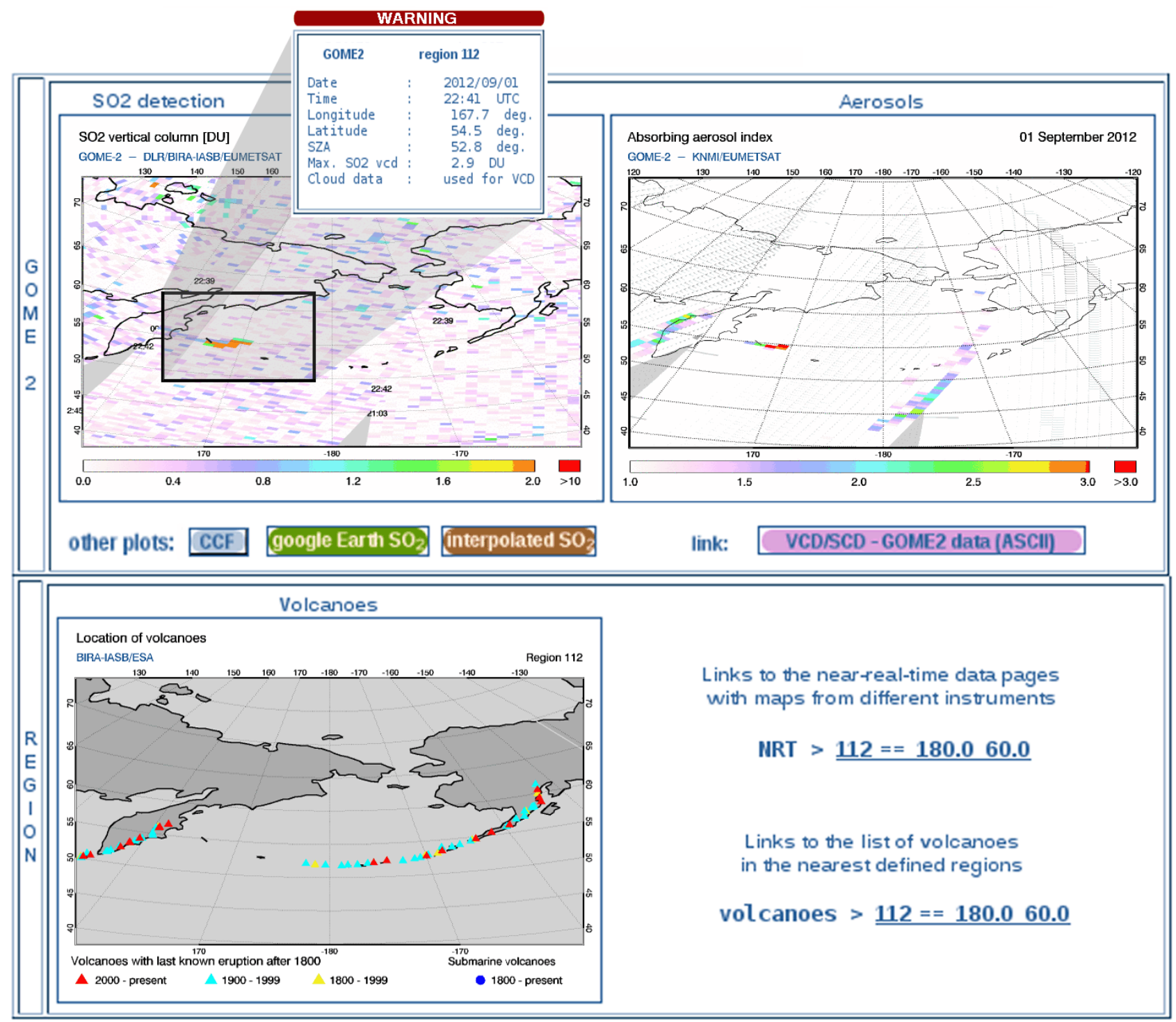

Fig. 11. $\mathrm{SO}_{2}$ and aerosol images from GOME-2A (notification web page), 1 September 2012 (eruption of the Bezymianny Volcano in the Kuril Islands).

Note that a solar zenith angle cut-off is used for each UVvisible sensor depending on the day of the year. The values have been determined empirically to have the best coverage while limiting the increase in the noise (instrument-specific).

\section{Dedicated $\mathrm{SO}_{2} /$ ash notifications web page}

An example of a web page generated by SACS using GOME$2 \mathrm{~A}$ data for a specific $\mathrm{SO}_{2}$ notification is shown in Fig. 11 . This notification was sent to the users $1 \mathrm{~h} 01 \mathrm{~min}$ after MetOp-A passed over this area. The page shows a box with the information given by the email notification (time of measurement, location of the warning, SZA, maximum $\mathrm{SO}_{2}$ value and the use of cloud data in calculations) and the images of $\mathrm{SO}_{2}$ and aerosols/ash side by side. Below the $\mathrm{SO}_{2}$ image, one can find two links to the same image but with different mapping tools (interpolated image using the Generic Mapping Tools from the University from Hawaii, see http://gmt.soest.hawaii.edu, and a Google Earth file, see http://www.google.com/earth). For the UV-visible instruments, there is also a link to the corresponding cloudcover fraction (CCF) image. In case of an IASI notification, in addition to the $\mathrm{SO}_{2}$ brightness temperature index image, there is also a link to the $\mathrm{SO}_{2} \mathrm{VCD}$ image. As a complement, a map showing the volcanoes in the region (with a link to a listing including more information about each of them) is also provided on this web page. Furthermore, a direct link to the near-real-time monitoring web page is given with all corresponding SACS images (for all instruments) and a link to 


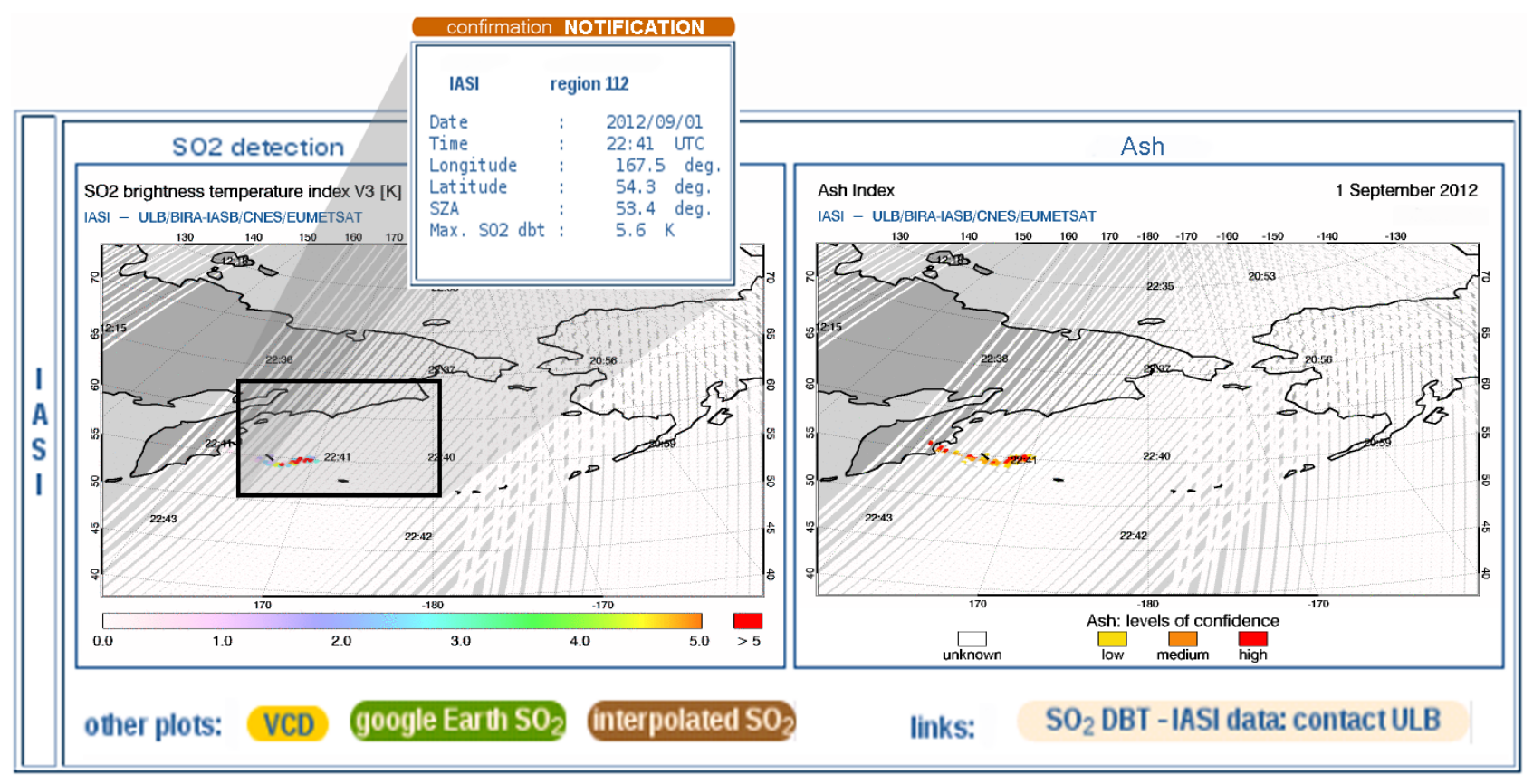

Fig. 12. $\mathrm{SO}_{2}$ and ash images, on 1 September 2012. Confirmation of notification by IASI-A.

the data (files or link to data providers) for the region considered.

\section{Confirmation of $\mathrm{SO}_{2} /$ ash notification}

For the example shown in Fig. 11, IASI-A also detected an $\mathrm{SO}_{2}$ signal and ash in region 112 (see Fig. 12) and acted as a confirmation. In fact the processing of IASI was just $3 \mathrm{~min}$ after that of GOME-2, which took place at 23:42 UTC, as shown in Fig. 10. No notification was sent to the users, as there already was a notification based on GOME-2, but the dedicated web page was automatically updated with the notification box for the IASI warning, using the same displaying template. Note that 2 and $10 \mathrm{~h}$ after this notification from GOME-2, two other instances of confirmation from AIRS and IASI took place.

\section{Update of $\mathrm{SO}_{2} /$ ash notification archive}

As soon as a warning is detected by the system, the warning archives are automatically updated on the SACS website. The warning subpage allows the users to select the instruments of interest for a given month/year and to visualise a map with the location of all the corresponding warnings (see next section). For a given region, a minimum delay of $12 \mathrm{~h}$ separates the time between two warnings, as explained above. The map of the notifications is an interactive map. When moving the cursor on a warning point, the user can visualise the images corresponding to the notification. In addition to this interactive tool, a common list with all the no- tifications (chronologically sorted) is also available with the relevant links to the different web pages.

\subsection{0 years of data and notifications archive}

Although the multi-sensor notification system has only been operational since April 2012, 10 years of historical data have been reanalysed for the development of the warning service. This section presents an overview of all the $\mathrm{SO}_{2}$ and ash notifications identified by SACS using the seven sensors (AIRS, OMI, SCIAMACHY, GOME-2A, IASI-A, GOME$2 \mathrm{~B}$ and IASI-B) on-board Aqua, Aura, Envisat, MetOp-A and MetOp-B. For each year (from 2004 to 2013), an image of all the notifications is shown with a highlight of the major events. This tool, available on the SACS portal, allows any interested person to investigate historical eruptive emissions in a quick and user-friendly way. In addition to our archive of exceptional volcanic emissions, note that our system also allows for the monitoring of small volcanic eruptions which might not always lead to a notification.

\subsubsection{Notifications from 2004 to 2006 (SCIAMACHY, OMI and AIRS)}

Data from the SCIAMACHY, OMI and AIRS instruments are available for this period (note that AIRS data are recorded from 2002 onwards). The main volcanic activity detected by SACS in 2004 was in the Independent State of Papua New Guinea, the archipelago of the Republic of Vanuatu and the Democratic Republic of Congo (DRC), as shown in Fig. 13a. The borderland between Rwanda, the DRC and 

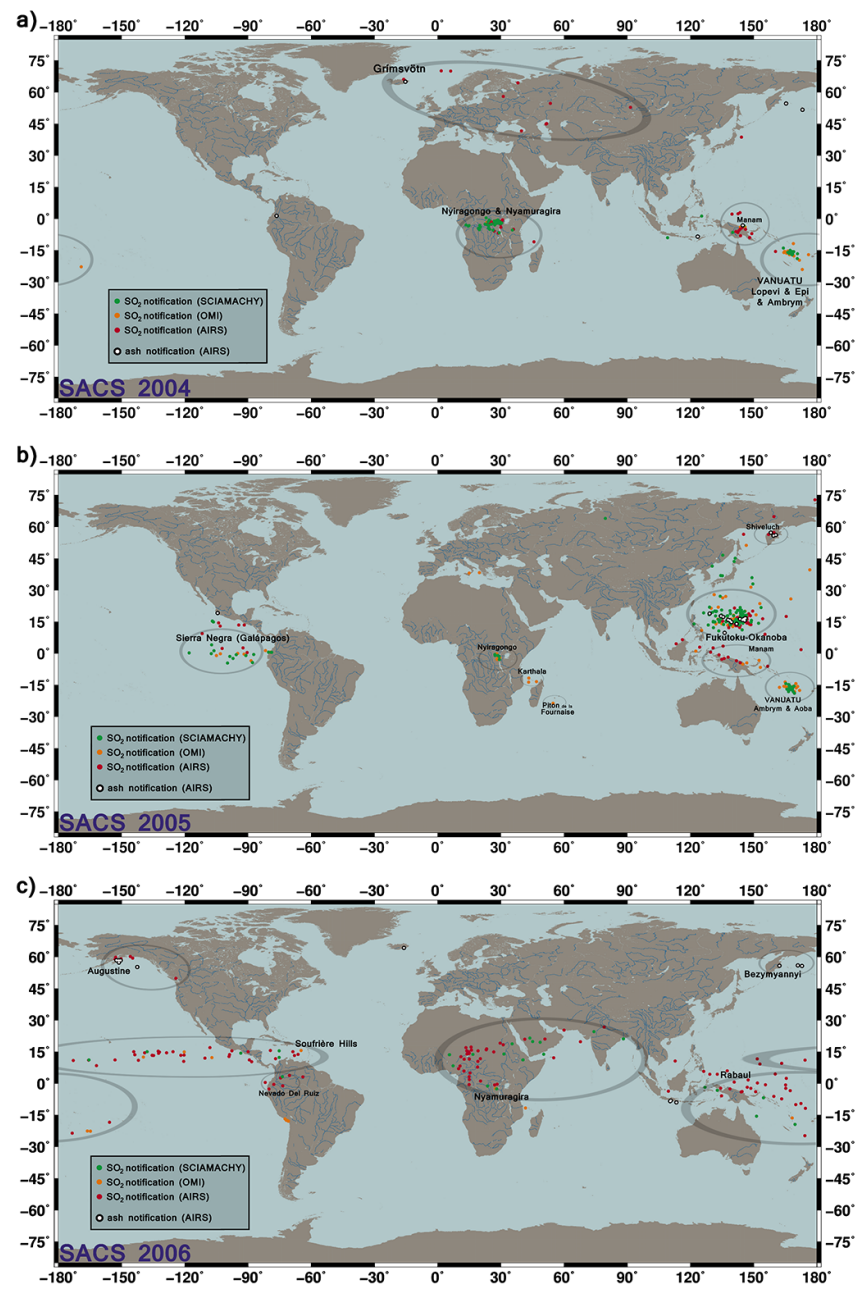

Fig. 13. SACS notifications for 2004, 2005 and 2006.

Uganda is one of the most active regions, containing eight volcanoes, including Mount Nyamuragira and Mount Nyiragongo which were both erupting on 25 May 2004. Details of the satellite monitoring of $\mathrm{SO}_{2}$ emissions from Nyamuragira from 1979 to 2005 can be found in Bluth and Carn (2008). Figure 13a also presents several $\mathrm{SO}_{2}$ and ash notifications over Europe in 2004. During the first week of November, an eruption occurred in Iceland (Grímsvötn Volcano). Volcanic ash from the eruption fell as far away as mainland Europe and caused short-term disruption of airline traffic into Iceland. Assuming an ash density of $2200 \mathrm{~kg} \mathrm{~m}^{-3}$ and using dispersion models from the VAACs, Witham et al. (2007) give an emission up to $9.50 \times 10^{12} \mathrm{~g} \mathrm{~h}^{-1}$ for the larger plume; that corresponds to an erupted mass of $3.3 \times 10^{11} \mathrm{~kg}$ and a volume of $0.15 \mathrm{~km}^{3}$ over the $35 \mathrm{~h}$ release period. Note that at this time of the year, the thermal IR sensor (AIRS) was the best instrument (best coverage and time laps between observations) to monitor the volcanic plume.

The volcanic activity in DRC (Galle et al., 2005) and in Galápagos and Vanuatu continued in 2005 as can be seen in
Fig. 13b. The signatures of two additional major eruptions are also visible: (1) the submarine eruption of the Japanese Fukutoku-Okanoba Volcano, located $6 \mathrm{~km}$ north-east of the pyramidal island of Minami Iwojima (about $1300 \mathrm{~km}$ southwest of Tokyo); the subsequent number of $\mathrm{SO}_{2}$ and ash notifications is shown Fig. 13b; (2) the eruption of the Sierra Negra volcano, Galápagos, Ecuador; after 26 of years being inactive and six months after an earthquake on an active fault, the volcanic activity of the Sierra Negra rose again on 22 October 2005 with a fissure opening inside the rim of the caldera, this eruption emitting a volcanic cloud with an estimated volume of 150 millions $\mathrm{m}^{2}$ of gas with a $2 \mathrm{~km}$-long curtain of lava fountains (Geist et al., 2008). During this effusive eruption, a huge amount of gas and particles was ejected into the low troposphere. The plume of $\mathrm{SO}_{2}$ and ash reached an estimated altitude of below $5 \mathrm{~km}$ (Yang et al., 2009). No ash notification has been identified by AIRS. At the end of October 2005, atmospheric emissions of this volcano ceased.

In 2006, volcanic activity was detected by SACS (Fig. 13c) in the Andes Cordillera (Colombia and Peru), in Kamchatka (Russian Federation) and in Alaska (United States of America), but the three strongest eruptions occurred in other parts of the world: (1) on 6 October, a large explosive eruption took place at Rabaul Volcano (Papua New Guinea), sending a plume of gas and ash up to the lower stratosphere; several notifications were issued by SACS showing the volcanic cloud travelling westward; (2) the Nyamuragira Volcano was also active in 2006; a strong eruption began in the night of 27 November (see, e.g., Prata and Bernardo, 2007) and the volcanic cloud initially moved north-eastward to finally travel to the west and pass over Pakistan and India; (3) the 20 May eruption of Soufrière Hills (Montserrat, British Overseas Territory) released a volcanic cloud which travelled over a very long distance (more than $18000 \mathrm{~km}$ westward); a large dome collapse was accompanied by a large explosion, producing a volcanic plume (with a low concentration of ash) up to $18 \mathrm{~km}$ high (Prata et al., 2007). Note that for this eruption, no ash has been detected by our algorithm for AIRS sensor. The movement of this volcanic cloud was monitored for 23 days (see Fig. 14), drifting westward and causing the diversion of many planes. On 20 May, at 17:02 UTC, the OMI sensor measured a VCD of up to 122.2 DU. Several days after the eruption, the wind rapidly dispersed the volcanic cloud in a north-easterly and south-westerly direction (22 and 24 May, Fig. 14). Note that for this date, the OMI sensor was not yet affected by the row anomaly and was still able to provide global coverage.

\subsubsection{Notifications from 2007 to 2012 (SCIAMACHY, OMI, AIRS, GOME-2A and IASI-A)}

Since 2007, $\mathrm{SO}_{2}$ and aerosols/ash observations from the GOME-2A and IASI-A instruments have been available and have been included in SACS. Volcanic emissions in 2007 have been observed by our system for some volcanoes of 


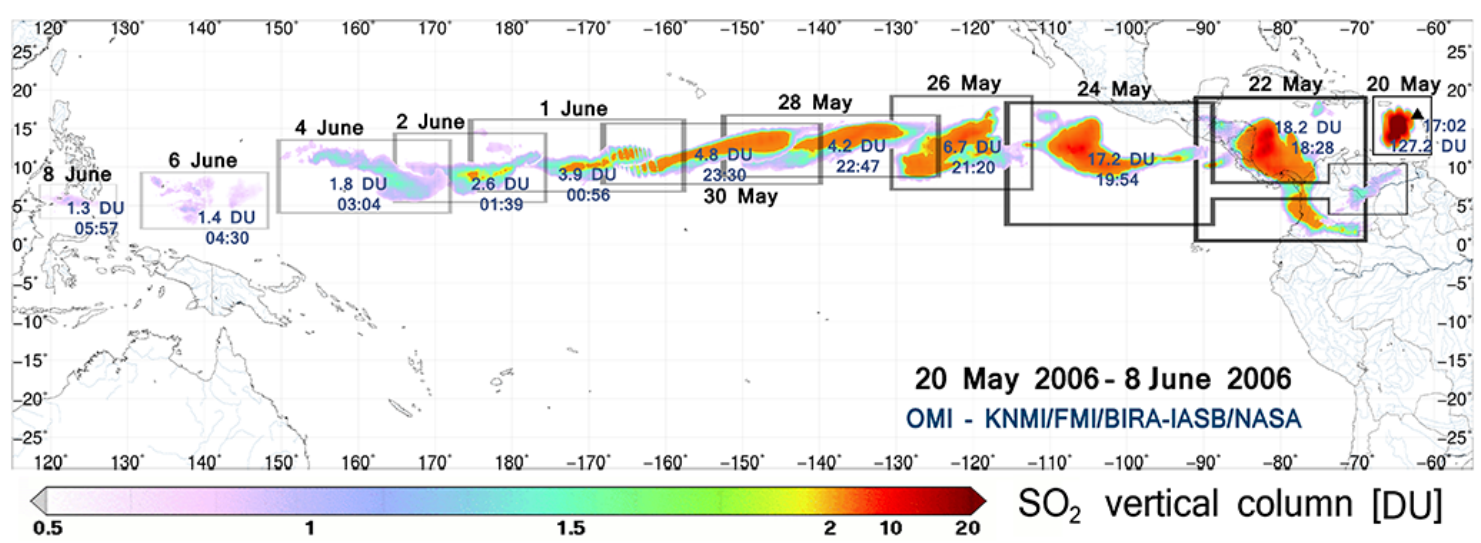

Fig. 14. OMI images of $\mathrm{SO}_{2}$ emitted by the Soufrière Hills volcano from 20 May to 8 June 2006 (from right to left).

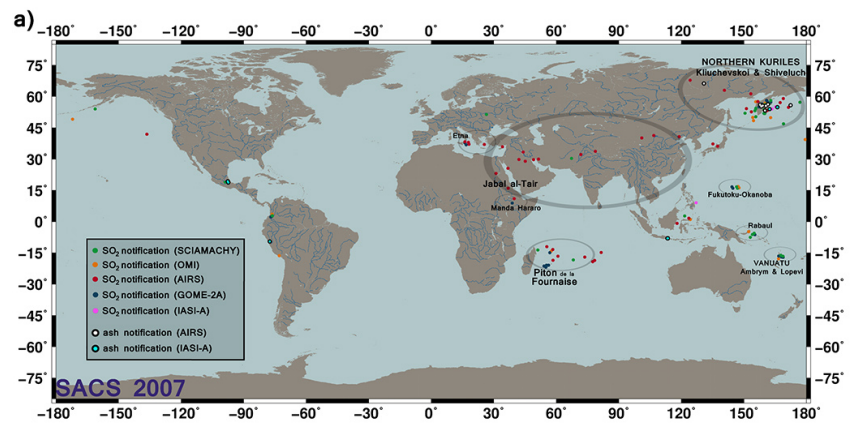

b) $-180^{\circ} \quad-150^{\circ} \quad-120^{\circ} \quad-90^{\circ} \quad-60^{\circ} \quad-30^{\circ} \quad 0^{\circ} \quad 30^{\circ} \quad 60^{\circ} \quad 90^{\circ} \quad 120^{\circ} \quad 150^{\circ} \quad 180^{\circ}$
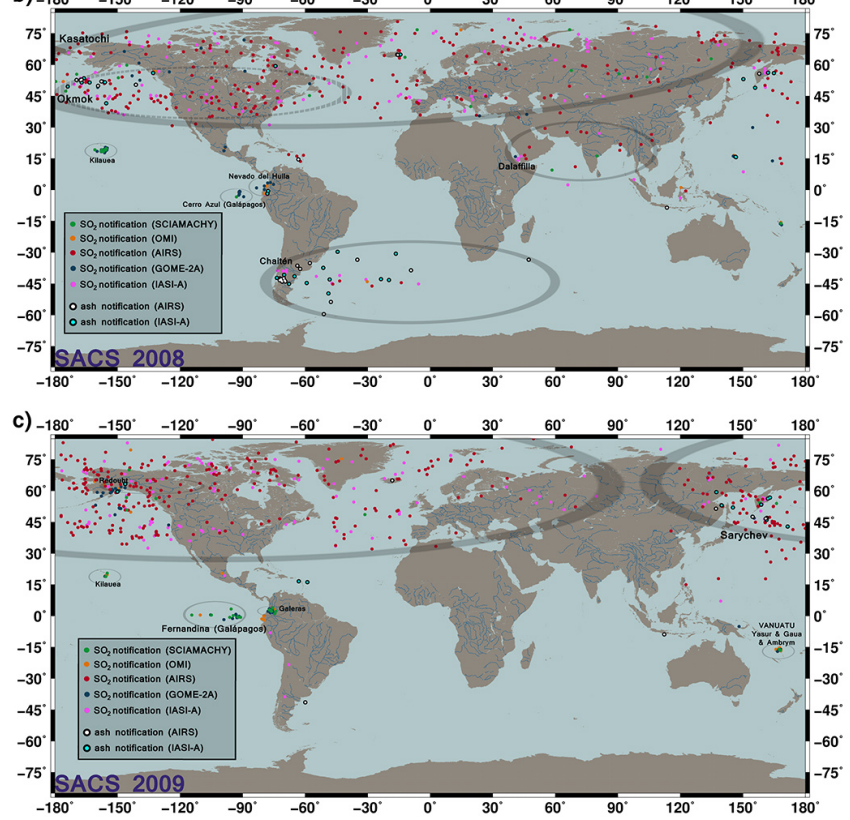

Fig. 15. SACS notifications for 2007, 2008 and 2009.

the Russian Federation (located in the northern Kuril Islands and in Kamchatka), as shown in Fig. 15a. In January 2007, the Klyuchevskoy Volcano started another eruption cycle. On 28 June, this volcano began to experience the largest ex-

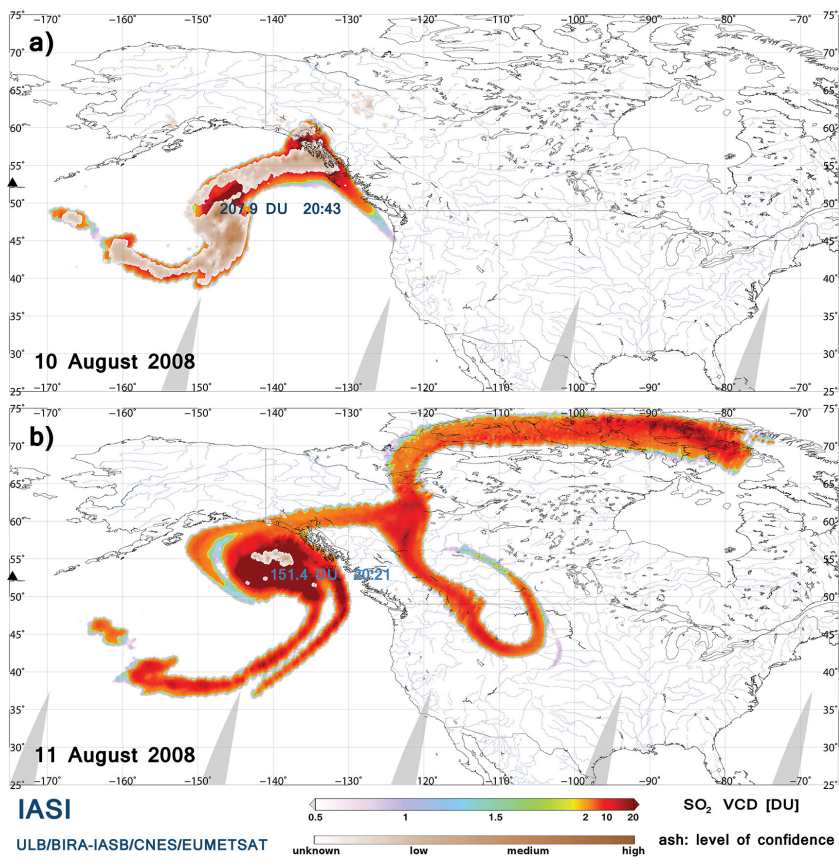

Fig. 16. IASI-A $\mathrm{SO}_{2}$ column density and ash index emitted by the Kasatochi Volcano on (a) 10 August 2008, and (b) 11 August 2008.

plosions so far recorded in that eruption cycle, disrupting air traffic from the United States to Asia and causing ashfalls on Alaska's Unimak Island. Volcanic activity has also been monitored by SACS in many other regions on Earth (although not all events are relevant for aviation), notably in Papua New Guinea (Rabaul Volcano), the archipelago of Vanuatu (Ambrym and Lopevi volcanoes), in Ecuador (Tungurahua Volcano), the Bonin Islands of Japan (FukutokuOkanoba), Italy (Etna) and in Ethiopia (Manda Hararo). The two largest eruptions of 2007 were observed at Jabal al-Tair Island (Yemen) and at Réunion Island (France). 


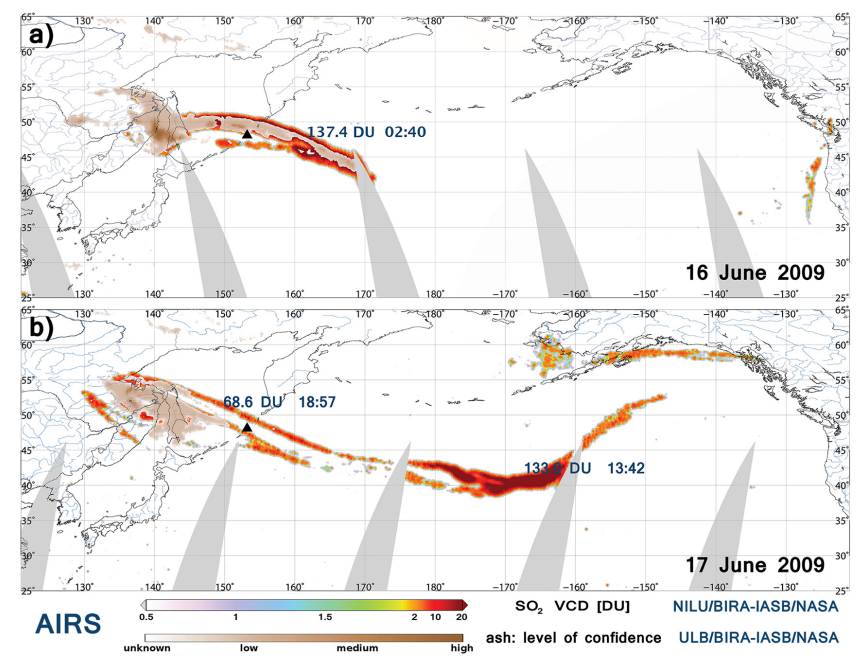

Fig. 17. AIRS $\mathrm{SO}_{2}$ column density and ash index emitted by the Sarychev Volcano on (a) 16 June 2009, and (b) 17 June 2009.
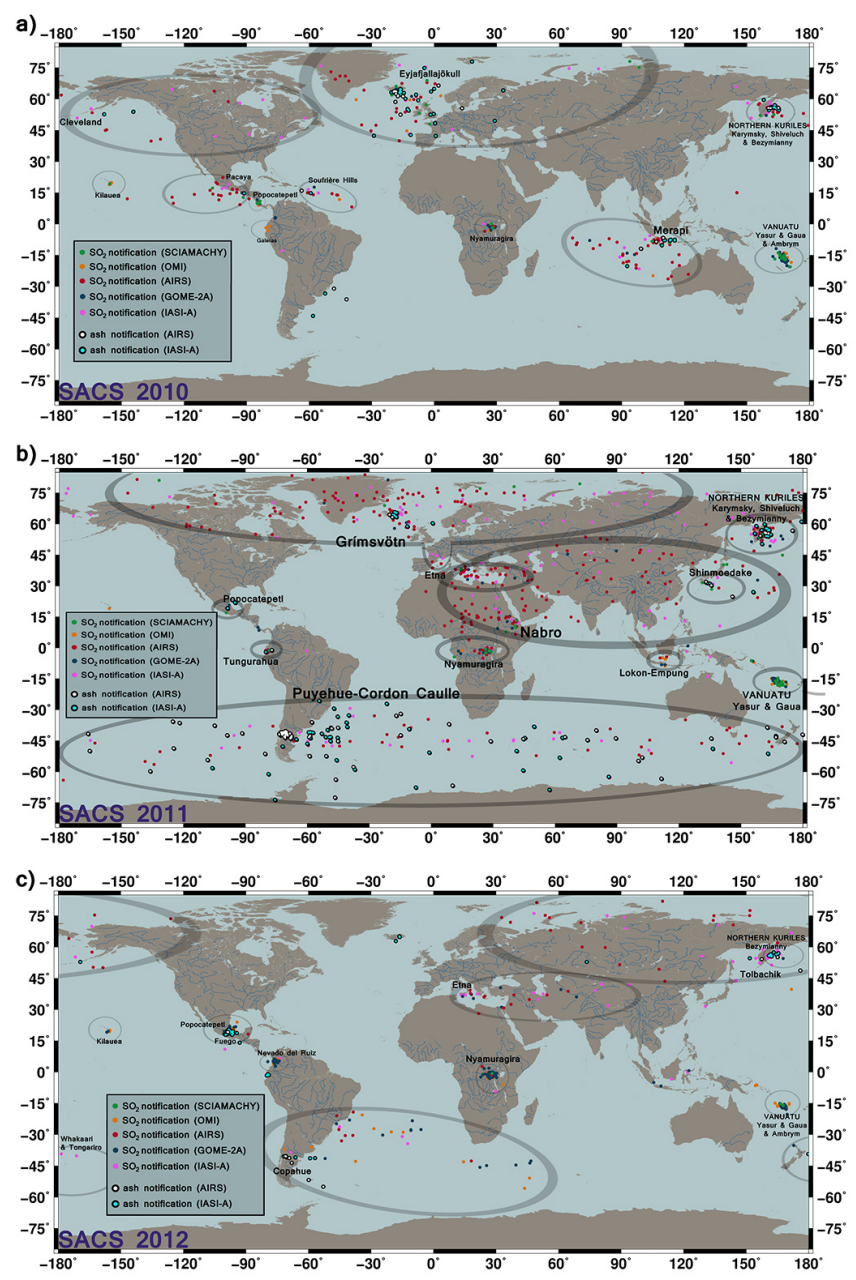

Fig. 18. SACS notifications for 2010, 2011 and 2012.
The Jabal al-Tair eruption started unexpectedly on 30 September 2007 after 124 years of dormancy. $\mathrm{SO}_{2}$ emitted during the initial eruption travelled rapidly northward over Egypt and eastward over Pakistan and India (Clarisse et al., 2008). The volcanic plume reached the low stratosphere at an altitude of about $16 \mathrm{~km}$ (Eckhardt et al., 2008; Clarisse et al., 2008; Yang et al., 2009). The eruption of Piton de la Fournaise (Réunion Island) started during the night of 30 March 2007. This was the largest eruption in 100 years in this region (Deroussi et al., 2009). On 2 April, the opening of a fissure produced a lava flow that reached the sea with a flux estimated at $100 \mathrm{~m}^{3} \mathrm{~s}^{-1}$. A degassing of up to $1800 \mathrm{~kg} \mathrm{~s}^{-1}$ was estimated for this day by Tulet and Villeneuve (2011). Their study of the temporal evolution of the $\mathrm{SO}_{2}$ emission shows a budget of $230 \mathrm{kt}$. This eruption stopped on 1 May.

The SACS notifications of 2008 are presented in Fig. 15b. Besides a few eruptions on the Galápagos Islands (Cerro Azul volcano) and the eruption of Dalaffilla Volcano (Ethiopia), the two most significant explosive eruptions happened at the Okmok and Kasatochi volcanoes (Aleutian Islands, Alaska, USA) in July and August respectively. These two eruptions have been studied extensively and more information can be found in the literature (e.g. Prata et al., 2010; Karagulian et al., 2010; Krotkov et al., 2010; Clarisse et al., 2011). These strong eruptions caused a real threat to air traffic over the North American continent (see affected regions Fig. 15b).

Figure 16 presents the $\mathrm{SO}_{2}$ cloud from Kasatochi as observed by IASI on 10 and 11 August (interpolation with a grid of $0.25^{\circ}$ by $0.25^{\circ}$ ). The ash images from IASI (showing the level of confidence of the detection) have been superimposed over the $\mathrm{SO}_{2}$ images. The ash and $\mathrm{SO}_{2}$ clouds show a similar pattern on 10 August (see Fig. 16a). Note that ash observed with a low level of confidence over the south of Alaska and the west of Canada is an artefact in the analysis of the spectrum and the process of ash detection. The volcanic plume emitted by Kasatochi was an $\mathrm{SO}_{2}$-rich cloud (up to 676.4 DU on 8 August). We can see on 11 August that the ash cloud detected is smaller than the $\mathrm{SO}_{2}$ cloud (see Fig. 16b).

Two months after the Kasatochi eruption, Dalaffilla Volcano erupted on 3 November. This volcano, located in the Afar region of Ethiopia, is one of the six volcanoes in the Erta Ale range. We can see in Fig. 15b that a few days after this eruption, which was the largest observed in Ethiopia in historical times, the volcanic cloud generated six $\mathrm{SO}_{2}$ notifications over India and the south of China.

Three major eruptions that occurred in 2009 were identified by the SACS warning service (Fig. 15c): Redoubt Volcano in Alaska, Fernandina Volcano in the Galápagos Islands, and Sarychev Volcano in the Kuril Islands. The explosive eruption of Sarychev (11-19 June 2009) emitted a huge amount of ash and $\mathrm{SO}_{2}$ into the atmosphere to a range of altitudes of 10-16 km (Carn and Lopez, 2011; Clarisse et al., 2012). The mass of the $\mathrm{SO}_{2}$ plume was estimated to be 

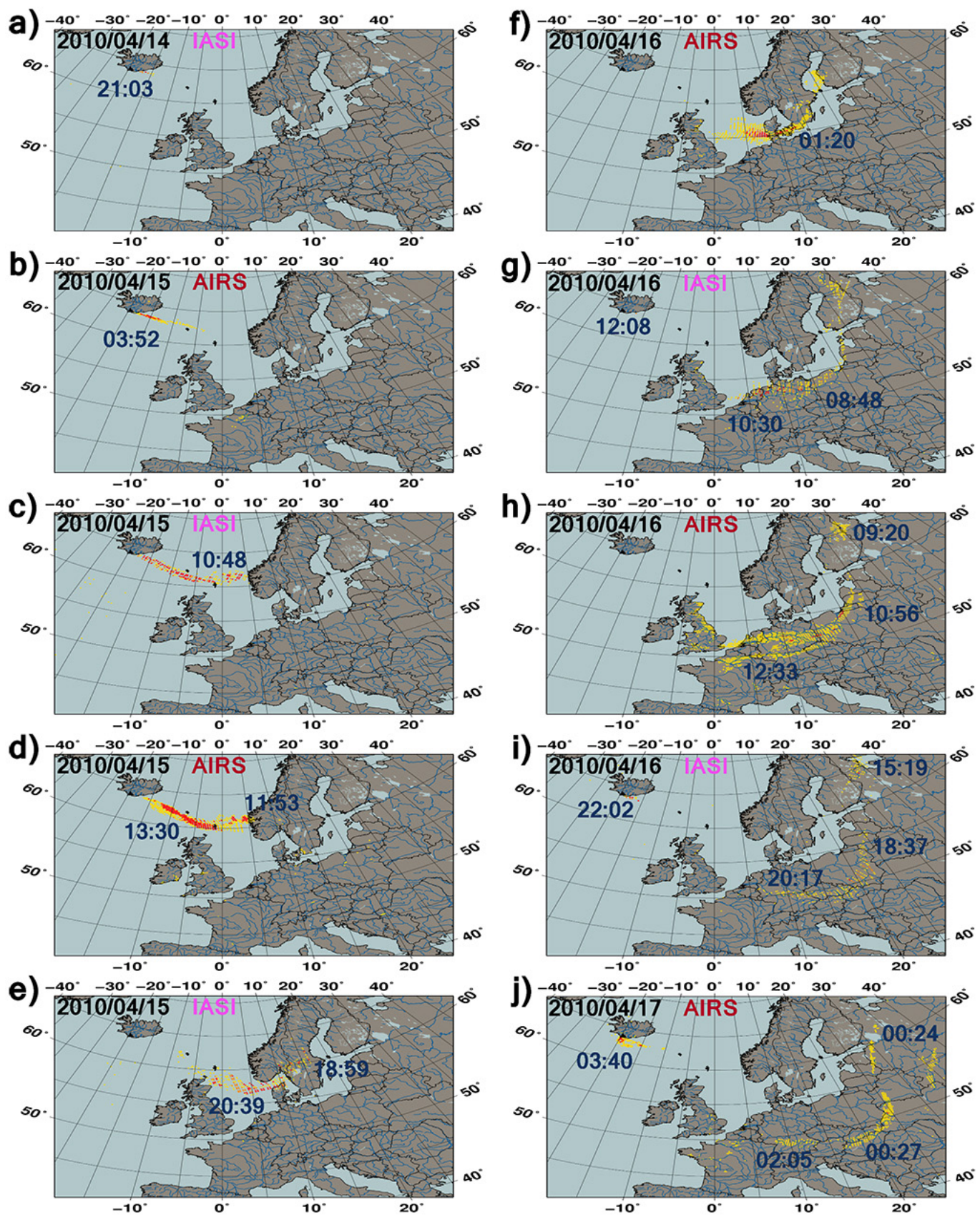

Ash: levels of confidence

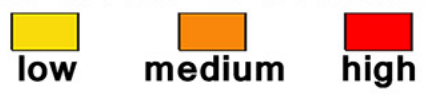

Fig. 19. Ash index images from thermal IR sensors (AIRS and IASI-A) during the eruption of the Eyjafjallajökull Volcano (Iceland) in spring 2010.

$1.2 \pm 0.2 \mathrm{Tg}$ by Haywood et al. (2010). This eruption, which was one of the 10 largest stratospheric injections in the last 50 years, significantly affected the radiative budget of the atmosphere (Haywood et al., 2010). Images of the $\mathrm{SO}_{2}$ and ash clouds observed by AIRS are shown in Fig. 17 (ash image superimposed over the $\mathrm{SO}_{2}$ image). We can see that the ash detection (with a low level of confidence) over the Russian land to the north of the Sea of Okhotsk is an artefact. On the morning (UTC time) of 16 June, $\mathrm{SO}_{2}$ and ash cloud are well co-located (see Fig. 17a). Note that the first $\mathrm{SO}_{2}$ plume was 


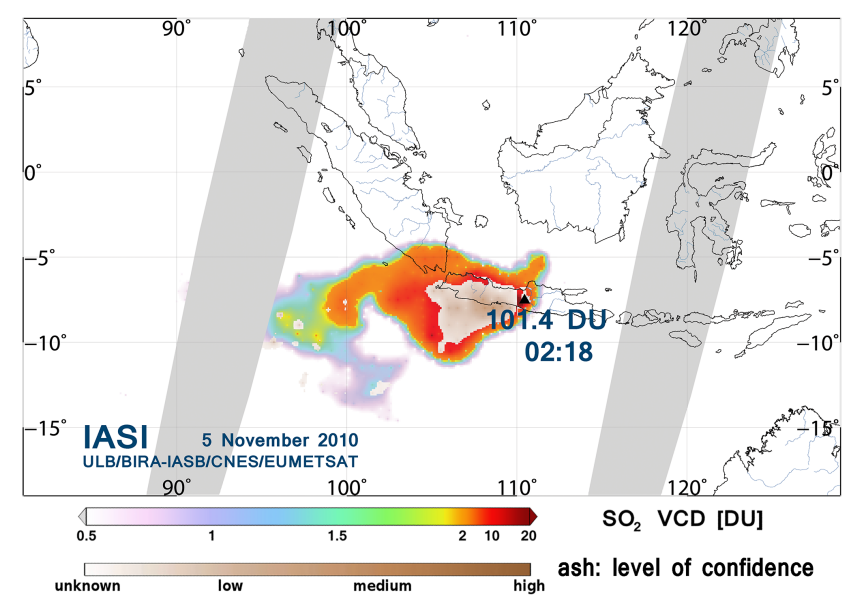

Fig. 20. Ash image superimposed over the $\mathrm{SO}_{2}$ image from IASI-A during Merapi's eruption (5 November 2010).

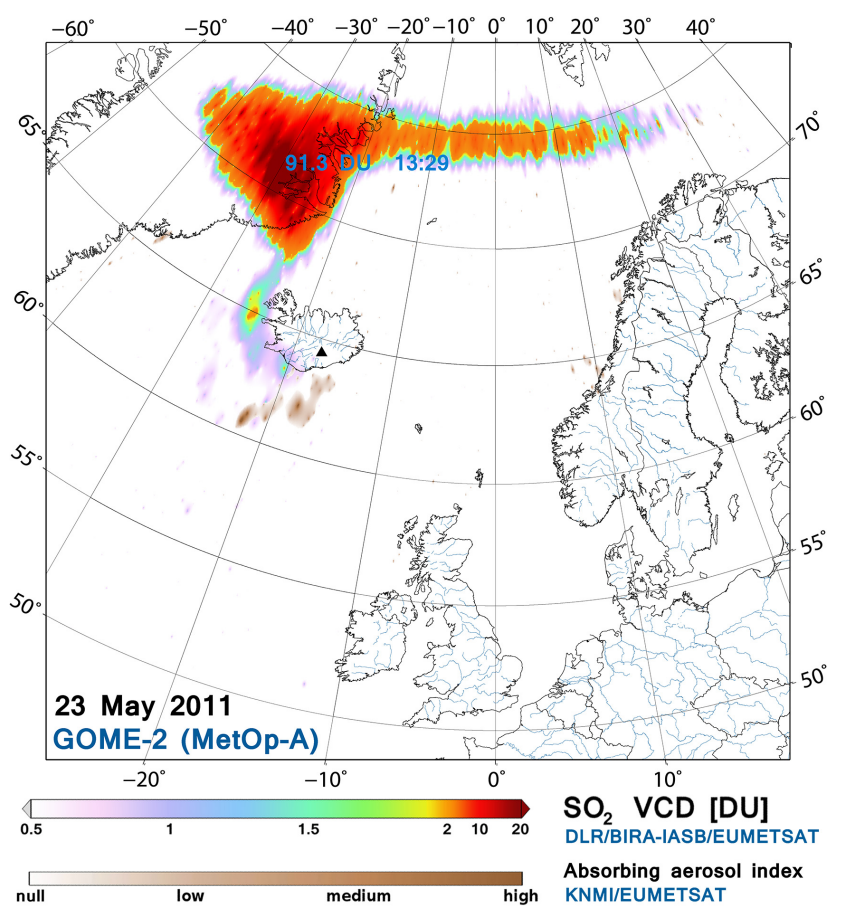

Fig. 21. $\mathrm{SO}_{2}$ and aerosols (ash) detected by GOME-2A (Grímsvötn eruption, 23 May 2011).

emitted two days before and was observed on the west coast of the USA. Figure $17 \mathrm{~b}$ shows the $\mathrm{SO}_{2}$ cloud observed on the afternoon of 17 June. The ash cloud detected by AIRS is located over the Russian Sakhalin Island. No ash was detected by AIRS over the Pacific ocean.

Figure 18a shows all the $\mathrm{SO}_{2}$ and ash notifications identified by SACS for the year 2010. Many regions were affected by volcanic activity. The 2010 eruptions of the Eyjafjallajökull Volcano in Iceland were relatively small, but unusual meteorological conditions brought volcanic ash clouds over Europe, causing enormous disruption to air traffic across western and northern Europe over an initial period of six days in April 2010 (Zehner, 2010). Additional localised disruption continued into May 2010. The eruption was declared officially over in October 2010, when snow falling on the glacier did not melt anymore. From 14 to 20 April, ash covered large areas of northern Europe when the volcano erupted (see Fig. 19 with images of the level of confidence of ash detection from AIRS and IASI from 14 April to 17 April). Most of the airports of northern Europe were closed by the authorities. During these days, the quantity of $\mathrm{SO}_{2}$ observed by UV-visible and IR satellites was low (less than $5 \mathrm{DU}$ ), possibly due to local chemical reactions between $\mathrm{SO}_{2}$ and water vapour creating sulfides or sulfuric acid. In May 2010, during the second phase of emissions, a more significant amount of $\mathrm{SO}_{2}$ was measured (up to 28.6 DU for AIRS on 6 May).

The strongest eruption of 2010 was the one of Merapi on 3 November on the Island of Java, Indonesia. Rapid ascent of magma from the depths of the volcano and the collapse of the lava dome put the large population living around the volcano in danger. People had to move away from their homes around the flanks of Merapi. For the first time, remote sensing (ground deformation by aperture radar, and monitoring of gas emissions by spectroscopic technique), together with the monitoring of the seismicity and the ground deformation by geodetic technique, provided precursory signals of this volcanic crisis, avoiding the death of several thousand people living nearby (Surono et al., 2012). Explosive and effusive phases took place and released a mass of $\mathrm{SO}_{2}$ of about $0.44 \mathrm{Tg}$. The altitude of the $\mathrm{SO}_{2}$ - and ash-rich plume was estimated to be about $12 \mathrm{~km}$. Figure 20 presents $\mathrm{SO}_{2}$ and ash measured by IASI on 5 November. Ash and $\mathrm{SO}_{2}$ were monitored by IASI for 10 and 15 days respectively after the start of the eruption. The five instruments used by SACS at this time (with their space and time complementarities) identified many $\mathrm{SO}_{2}$ /ash notifications (see Fig. 18a) and allowed a good monitoring of Merapi's eruption and its volcanic cloud (eastward movement and then southward).

The largest number of notifications of the SACS system to date occurred during the year 2011 (Fig. 18b). The three major events of 2011 were the eruptions of the Icelandic Grímsvötn Volcano (21-28 May), the eruption of the Chilean Puyehue-Cordón Caulle volcano (4-7 June) and the eruption of the Eritrean Nabro Volcano (12 June-7 July). A characteristic feature of the Grímsvötn eruption is that a large amount of $\mathrm{SO}_{2}$ was ejected northwards while the ash cloud went to the south-east (see GOME-2 image, Fig. 21). In this figure, the image of the absorbing aerosols index has been superimposed onto the $\mathrm{SO}_{2}$ image. The null, low, medium and high level of aerosols/ash detected by GOME-2 corresponds respectively to AAI of under 2, AAI of 2.5, AAI of 3 and AAI over 3.5. Aerosol detection on the north coast of Norway is not related to the Grímsvötn eruption. The $\mathrm{SO}_{2}$ cloud, which travelled over Canada and came back over Europe, was monitored for 3 weeks. The ash cloud, which travelled 

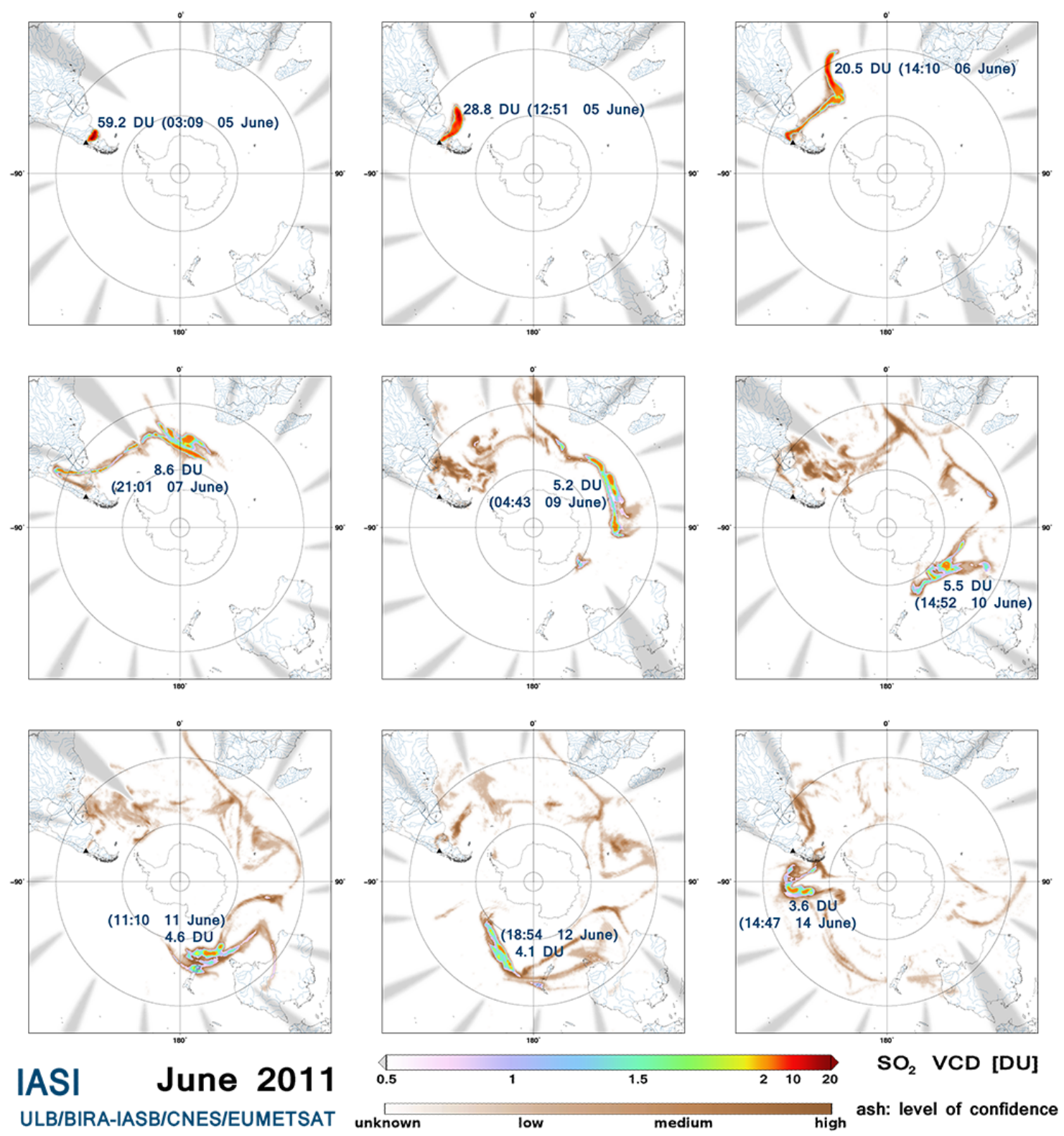

Fig. 22. $\mathrm{SO}_{2}$ and ash detected by IASI-A (Puyehue-Cordón Caulle eruption, 6 June 2011).

over Europe, was under the limit of detection 3 days after the start of the eruption.

On 4 June 2011, the eruption of the Puyehue-Cordón Caulle volcano started. Out of the 12 years the $\mathrm{SO}_{2}$ and ash notification archives span (from 2002 to 2014), this eruption is the most ash rich recorded by our system. The volcanic cloud emitted was an ash-laden plume. During the first two days of this eruption, the $\mathrm{SO}_{2}$ and ash clouds were colocated. Afterwards, the volcanic cloud dispersed and circled around the South Pole (see Fig. 22). Within a few day, the cloud of ash covered the main part of southern high latitudes. Note that for this particular eruption, which occurred during the Austral winter, the UV sensors had limited coverage and IASI and AIRS were the only sensors able to track the volcanic plume globally. The $\mathrm{SO}_{2}$ and ash clouds were observed by IR sensors during 3 and 5 weeks respectively. The volcanic ash emitted by Puyehue consequently disturbed the air traffic of the Southern Hemisphere during the month of June 2011 in Chili, Argentina, Uruguay, Brazil, South Africa, Australia and New Zealand.

During the night of 12 June 2011, the Eritrean Nabro Volcano started to erupt (see Fig. 3). This explosive eruption ejected a huge amount of $\mathrm{SO}_{2}$ in the atmosphere, threatening international routes from the Far East to Europe. On 14 June, the Nabro Volcano spewed a volcanic plume across the route of many flights over east Africa and the Middle East. 


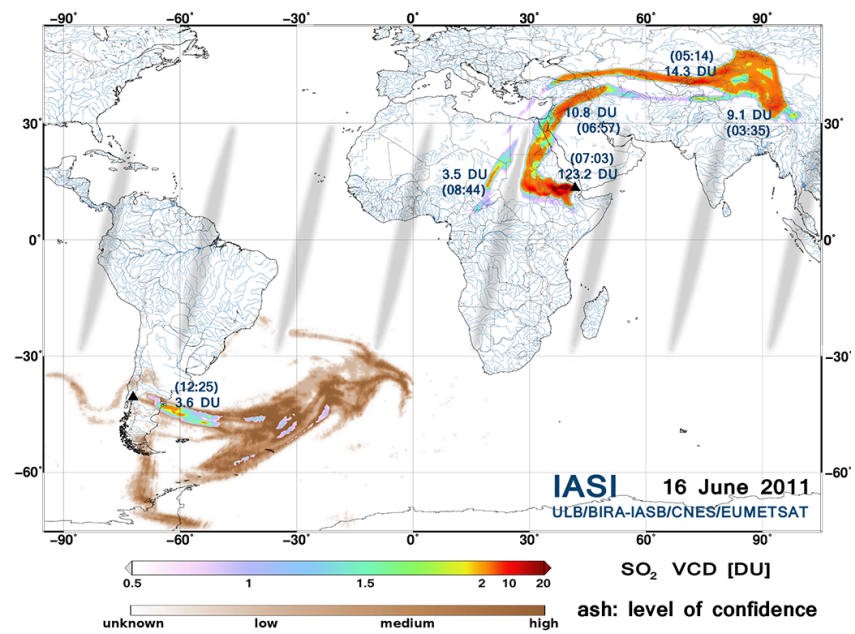

Fig. 23. $\mathrm{SO}_{2}$ and ash detected by IASI-A (Nabro and Puyehue eruptions, 16 June 2011).

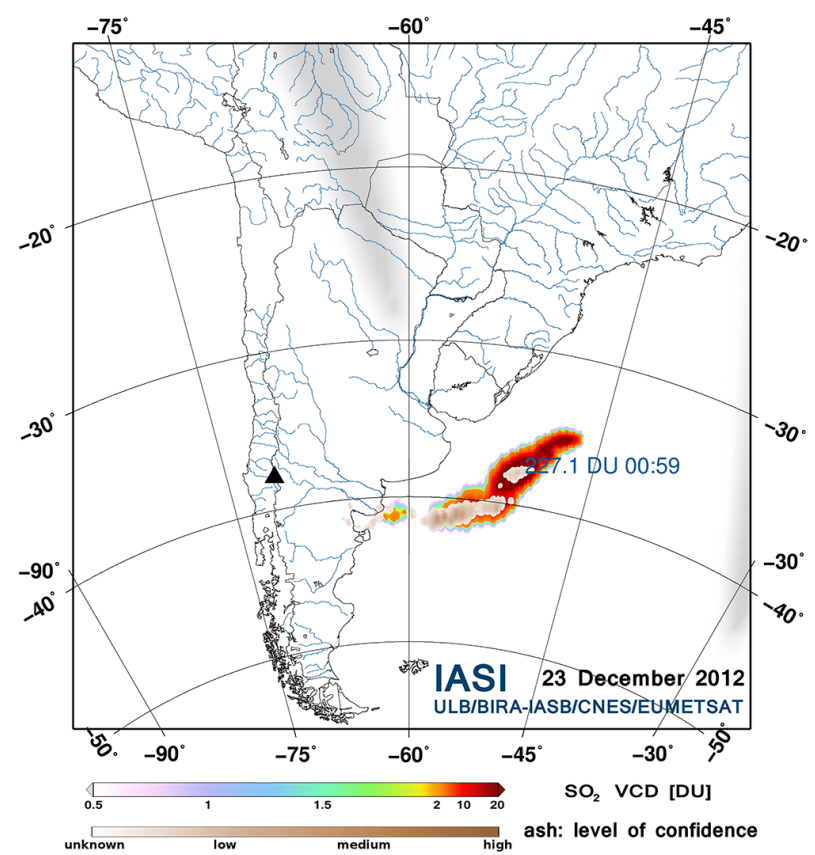

Fig. 24. $\mathrm{SO}_{2}$ and ash detected by IASI-A (Copahue eruption, 23 December 2012).

Satellite information was critical in monitoring the journey of the volcanic cloud. We can see in Fig. 3 the cloud of $\mathrm{SO}_{2}$ detected by IASI and AIRS on 13 and 14 June. Figure 23 shows the $\mathrm{SO}_{2}$ plume observed by IASI during the night of 15-16 June. The amount of ash emitted by Nabro for this eruption was very low (and largely undetected by IASI and AIRS), while the ash emitted by the Puyehue Volcano was still detected by IASI (Fig. 23).

Figure 18c shows the SACS notifications for 2012. Continuous activity was recorded at the Nyamuragira Volcano

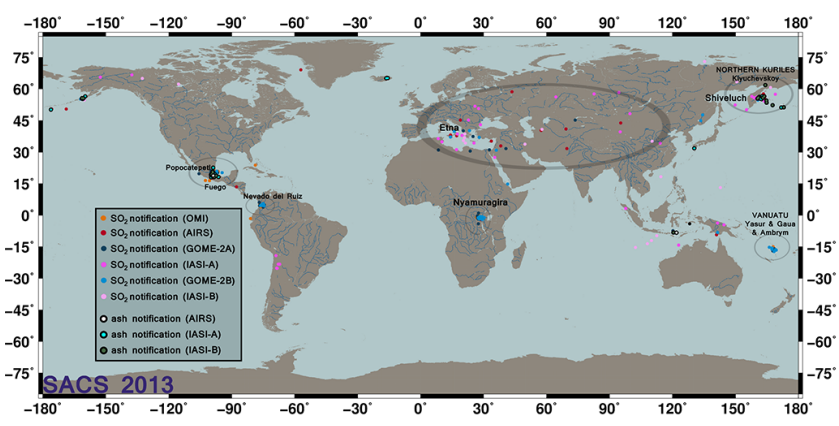

Fig. 25. SACS notifications for 2013.
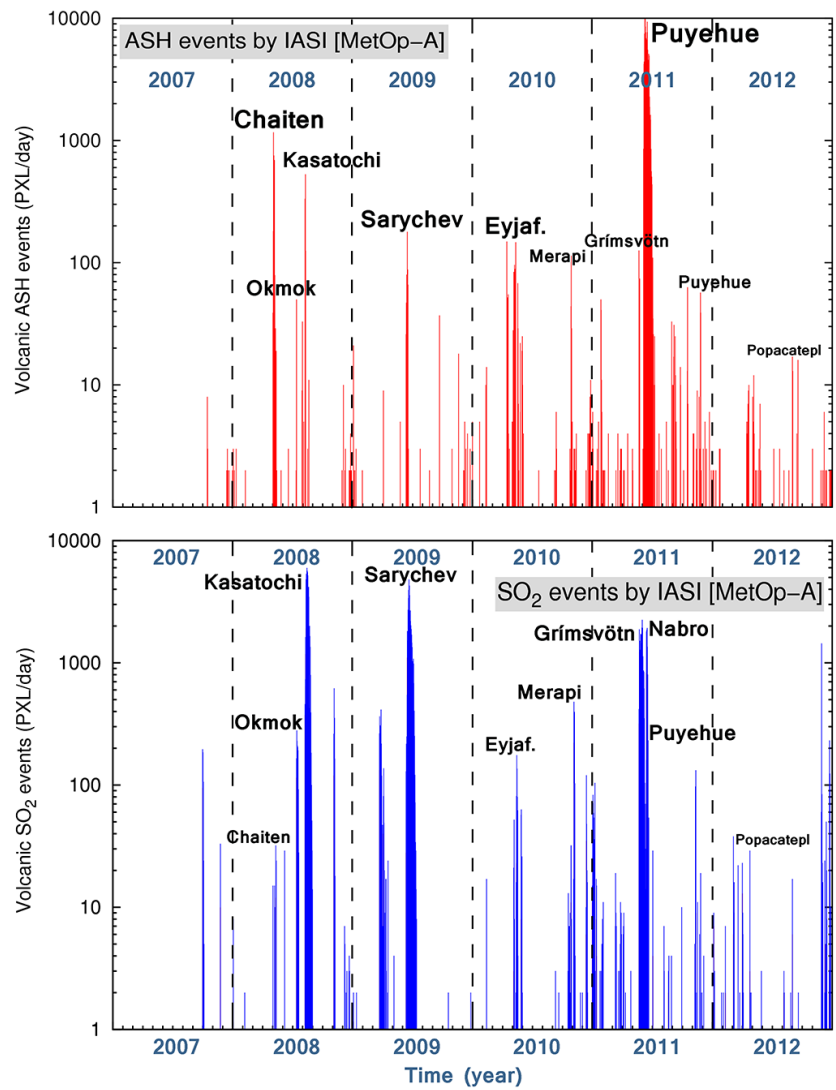

Fig. 26. Time series of the number of detections per day of ash (upper panel) and $\mathrm{SO}_{2}$ (lower panel) by IASI-A for the period 20072013.

(DRC). Summit eruptions of Etna (Italy) were also detected by SACS in January-April 2012, and again in July-October 2012, but no strong disruption of air traffic occurred. On 1 September 2012, an explosive eruption took place at Bezymianny Volcano (Kamchatka), producing an $\mathrm{SO}_{2}$ and ash cloud (see Figs. 11 and 12). With a cloud rising to an altitude of about $10 \mathrm{~km}$, the Tokyo VAAC sent out an ash-cloud aviation warning and the major intercontinental routes that pass through that area were cancelled. Less than two months after this eruption, a nearby volcano, Tolbachik, erupted on 
27 November. The main part of the volcanic ejection drifted north and north-west (NNW), as observed by IASI and AIRS sensors. At this time of the year and for this location, the thermal IR instruments were the only instruments used by SACS that were able to monitor the volcanic cloud. The ash advisory board from the Tokyo VAAC reported an ash cloud at an altitude of $10 \mathrm{~km}$, spreading to the NNW. Despite this, no ash was detected by the instruments used by SACS.

The last 2012 eruption which caused a disruption to air traffic, was the eruption of the Chilean Copahue Volcano (23-25 December). An $\mathrm{SO}_{2}$-rich plume associated with ash emissions was spewed into the sky (Fig. 24). The volcanic plume was transported over Chile and aviation authorities in South America warned airlines to avoid the area. Contrary to the previous eruption of Puyehue in June 2011, the Copahue's volcanic cloud was not particularly ash rich. We can see in Fig. 24 that for the first day of this eruption, $\mathrm{SO}_{2}$ and ash clouds took the same trajectory; nevertheless, the highest concentrations of $\mathrm{SO}_{2}$ and ash are not exactly at the same locations.

\subsubsection{Notifications in 2013 (OMI, AIRS, GOME-2A, IASI-A, GOME-2B, IASI-B)}

Since December 2012, $\mathrm{SO}_{2}$ and aerosols/ash observations from the GOME-2 and IASI instruments (on-board MetOpB) have been available and have been included in SACS. The most active volcanoes have been Etna and Popocatepetl. The first ash notifications sent to users by SACS (IASI-A, confirmation by IASI-B) was sent on 19 November 2013 for a plume emitted by Klyuchevskoy Volcano (Kamchatka). Only a small disruption of air traffic occurred because of this eruption; nevertheless, the change of the routes of several flights was adopted by airline companies.

This section illustrates the ability of the system to characterise different scenarios and volcanic cloud compositions $\left(\mathrm{SO}_{2}\right.$ rich, ash rich or both). In the time series presented in Fig. 26, the number of conclusive detections of ash and $\mathrm{SO}_{2}$ of the IASI-A instrument is shown for six years of operation.

\section{Conclusions and outlook}

In this paper, we have shown that the major volcanic events that have disturbed air traffic during the last 10 years have been detected by our system. Ash and $\mathrm{SO}_{2}$ emitted from volcanoes poses a significant threat to aircraft. Once ash is sucked into the aircraft's engines, it readily melts and can potentially cause engine failure. Furthermore, the path of an aircraft through a sulfur-rich volcanic cloud causes a deterioration of the engine with extra maintenance costs. Europe, North America, the north Atlantic and Asian regions have the highest air traffic densities, with an estimated rate of growth of about 2 to $5 \%$ per year during the period 1990-2050 (ESCAP, 2005). With the increase of commercial and freight air traffic, the increase of volcano surveillance is critically needed for future aircraft safety (Prata, 2009) and the nearreal-time monitoring of ash and $\mathrm{SO}_{2}$ from satellite sensors is essential.

Focussing on instruments on-board polar-orbiting platforms, this study presents the Support to Aviation Control Service. This free service provides images of $\mathrm{SO}_{2}$ and ash in near real time on a global scale via a web interface (http://sacs.aeronomie.be). We have set up a notification system and demonstrated that it is able to detect major volcanic events that occurred during the last decade and posed a threat to aviation. The current system uses in-synergy data products from UV-visible sensors (OMI, GOME-2/MetOp$\mathrm{A}$ and GOME-2/MetOp-B) and thermal IR sensors (AIRS, IASI/MetOp-A and IASI/MetOp-B) with a revisiting time of (at least) $6 \mathrm{~h}$ anywhere on Earth. We have assessed the limitations of our system and estimated the success rate of the notifications to be larger than $95 \%$

Finally, the next objectives for our service are:

- to incorporate more sensors in the system: in particular OMPS (Ozone Mapping Profiler Suite), CrIS (Crosstrack Infrared Sounder) and VIIRS (Visible Infrared Imaging Radiometer Suite) on the Suomi National Polar-orbiting Partnership mission (Suomi NPP) and TROPOMI (TROPOspheric Monitoring Instrument) on-board Sentinel 5 Precursor;

- to improve satellite data products for ash (as an outcome of the on-going SACS2 project);

- to provide information in NRT on volcanic $\mathrm{SO}_{2}$ plume height from satellite observations (e.g. Van Gent et al., 2014; Clarisse et al., 2013b);

- to implement new visualisation tools and different levels of notification, in line with the users' needs; in particular, customised notifications will be set up to trigger volcanic plume dispersion modelling and forecasts as part of the ESA VAST project (http://vast.nilu.no). 
Acknowledgements. Many thanks to ESA for the funding (SACS, SACS+ and SACS2 projects) and the support. We are grateful to NASA and FMI for the very fast delivery of OMI, CNES and EUMETSAT for data of IASI and GOME-2. We thank also JPL/NASA for the free access to AIRS data on EOSDIS. We would like also to acknowledge the team from the Toulouse VAAC (Météo-France), the London VAAC (UK Met Office), the Darwin VAAC (Bureau of Meteorology), the Anchorage VAAC (NOAA), the Wellington VAAC (MetService), the Montréal VAAC (Government of Canada) and all the users for their very useful feedback, which brings us energy and motivation and helps us to continue and to improve our service. The authors thank the reviewers for their comments and suggestions. This work was also undertaken under the auspices of the O3M SAF project of the EUMETSAT. P. F. Coheur and L. Clarisse are respectively Research Associate and Postdoctoral Researcher with F.R.S.-FNRS. The research in Belgium was funded by the F.R.S.-FNRS, the Belgian State Federal Office for Scientific, Technical and Cultural Affairs and the European Space Agency (ESA-Prodex arrangements C-4000103226). Financial support by the "Actions de Recherche Concertées" (Communauté Française de Belgique) is also acknowledged.

Edited by: A. Mugnai

Reviewed by: F. Cairo and one anonymous referee

\section{References}

Aumann, H. H., Gregorich, D., Gaiser, S., Hagan, D., Pagano, T., Strow, L. L., and Ting, D.: AIRS Algorithm Theoretical Basis Basis Document, Level 1B, Part 1: Infrared Spectrometer, Version 2.2i, 10 November 2000.

Aumann, H. H., Chahine, M. T., Gautier, C., Goldberg, M. D., Kalnay, E., McMillin, L. M., Revercomb, H., Rosenkranz, P. W., Smith, W. L., Staelin, D. H., Strow, L. L., and Susskind, J.: AIRS/AMSU/HSB on the Aqua mission: Design, science objectives, data products, and processing systems, IEEE T. Geosci. Remote, 41, 253-264, 2003.

Baxter, P. J., Bonadonna, C., Dupree, R., Hards, V. L., Kohn, S. C., Murphy, M. D., Nichols, A., Nicholson, R. A., Norton, G., Searl, A., Sparks, R. S. J., and Vickers, B. P.: Cristobalite in volcanic ash of the Soufriere Hills Volcano, Montserrat: Hazards implications, Science, 283, 1142-1145, doi:10.1136/oem.59.8.523, 1999.

Bluth, G. J. S. and Carn, S. A.: Exceptional sulfur degassing from Nyamuragira volcano, 1979-2005, Int. J. Remote Sens. (Special Issue: Advances in the Remote Sensing of Volcanic Activity and Hazards), 29, 6667-6685, doi:10.1080/01431160802168434, 2008.

Bovensmann, H., Burrows, J. P., Buchwitz, M., Frerick, J., Noël, S., Rozanov, V. V., Chance, K. V., and Goede, A. P. H.: SCIAMACHY: Mission objectives and Measurement Modes, J. Atm. Sci., 56, 127-150, doi:10.1175/15200469(1999)056<0127:SMOAMM>2.0.CO;2, 1999.

Cantor, R.: Complete avoidance of volcanic ash is only procedure that guarantees flight safety, ICAO Mag., 53, 18-19, 1998.

Carn, S. A. and Lopez, T. M.: Opportunistic validation of sulfur dioxide in the Sarychev Peak volcanic eruption cloud, Atmos. Meas. Tech., 4, 1705-1712, doi:10.5194/amt-4-1705-2011, 2011.
Carn, S. A., Krueger, A. J., Krotkov, N. A., Arellano, S., and Yang, K.: Daily monitoring of Ecuadorian volcanic degassing from space, J. Volcanol. Geotherm. Res., 176, 141-150, doi:10.1016/j.jvolgeores.2008.01.029, 2008.

Casadevall, T. J.: The 1989/1990 eruption of Redoubt Volcano Alaska: impacts on aircraft operations, J. Volcanol. Geotherm. Res., 62, 301-316, doi:10.1016/0377-0273(94)90038-8, 1994.

Casadevall, T. J., Delos Reyes, P. J., and Schneider, D. J.: The 1991 Pinatubo eruptions and their effects on aircraft operations, in: Fire and mud: eruptions and lahars of Mount Pinatubo, Philippines, edited by: Newhall, C. G. and Punongbayan, R. S., Philippines Institute of Volcanology and Seismology, Quezon City, University of Washington Press, Seattle, 625-636, 1996.

Clarisse, L., Coheur, P. F., Prata, A. J., Hurtmans, D., Razavi, A., Phulpin, T., Hadji-Lazaro, J., and Clerbaux, C.: Tracking and quantifying volcanic $\mathrm{SO}_{2}$ with IASI, the September 2007 eruption at Jebel at Tair, Atmos. Chem. Phys., 8, 7723-7734, doi:10.5194/acp-8-7723-2008, 2008.

Clarisse, L., Prata, F., Lacour, J.-L., Hurtmans, D., Clerbaux, C., and Coheur, P.-F.: A correlation method for volcanic ash detection using hyperspectral infrared measurements, Geophys. Res. Lett., 37, L19806, doi:10.1029/2010GL044828, 2010.

Clarisse, L., Coheur, P.-F., Chefdeville, S., Lacour, J. L., Hurtmans, D., and Clerbaux, C.: Infrared satellite observations of hydrogen sulfide in the volcanic plume of the August 2008 Kasatochi eruption, Geophys. Res. Lett., 398, L10804, doi:10.1029/2011GL047402, 2011.

Clarisse, L., Hurtmans, D., Clerbaux, C., Hadji-Lazaro, J., Ngadi, Y., and Coheur, P.-F.: Retrieval of sulphur dioxide from the infrared atmospheric sounding interferometer (IASI), Atmos. Meas. Tech., 5, 581-594, doi:10.5194/amt-5-581-2012, 2012.

Clarisse, L., Coheur, P.-F., Prata, F., Hadji-Lazaro, J., Hurtmans, D., and Clerbaux, C.: A unified approach to infrared aerosol remote sensing and type specification, Atmos. Chem. Phys., 13, 21952221, doi:10.5194/acp-13-2195-2013, $2013 \mathrm{a}$.

Clarisse, L., Coheur, P.-F., Theys, N., Hurtmans, D., and Clerbaux, C.: The 2011 Nabro eruption, a $\mathrm{SO}_{2}$ plume height analysis using IASI measurements, Atmos. Chem. Phys. Discuss., 13, 3116131196, doi:10.5194/acpd-13-31161-2013, 2013b.

Clerbaux, C., Boynard, A., Clarisse, L., George, M., Hadji-Lazaro, J., Herbin, H., Hurtmans, D., Pommier, M., Razavi, A., Turquety, S., Wespes, C., and Coheur, P.-F.: Monitoring of atmospheric composition using the thermal infrared IASI/MetOp sounder, Atmos. Chem. Phys., 9, 6041-6054, doi:10.5194/acp-9-6041-2009, 2009.

Deroussi, S., Diament, M., Feret, J., Nebut, T., and Staudacher, T.: Localization of cavities in a thick lava flow by microgravimetry, J. Volcanol. Geotherm. Res., 184, 193-198, doi:10.1016/j.jvolgeores.2008.10.002, 2009.

Eckhardt, S., Prata, A. J., Seibert, P., Stebel, K., and Stohl, A.: Estimation of the vertical profile of sulfur dioxide injection into the atmosphere by a volcanic eruption using satellite column measurements and inverse transport modeling, Atmos. Chem. Phys., 8, 3881-3897, doi:10.5194/acp-8-3881-2008, 2008.

ESCAP: Review of developments in transport in Asia and the Pacific 2005, United Nations Publ., No. E.06.II.F.9, ST/ESCAP/2392, 172 pp., 2005. 
Forbes, L., Jarvis, D., Potts, J., and Baxter, P. J.: Volcanic ash and respiratory symptoms in children on the island of Montserrat, British West Indies, Occup. Environ. Med., 60, 207-211, 2003.

Galle, B., Bobrowski, N., Carn, S., Durieux, J., Johansson, M., Kasereka, M., Oppenheimer, C., Yalire, M., and Zhang, Y.: Gas emissions from Nyiragongo volcano D. R. of Congo, measured by UV mini-DOAS spectroscopy, Geophysical Research Abstracts, Vol. 7, EGU General Assembly, Vienna, Austria, 9-22005, 2005.

Geist, D. J., Harpp, K. S., Naumann, T. R., Poland, M., Chadwick, W. W., Hall, M., and Rader, E.: The 2005 eruption of Sierra Negra volcano, Galápagos, Ecuador. Bull. Volc., 70, 655-673, 2008.

Guffanti, M., Casadevall, T. J., and Budding, K.: Encounters of aircraft with volcanic ash clouds: A compilation of known incidents, 1953-2009: U.S. Geological Data Series 545, ver. 1.0, 12 p., plus 4 appendixes including the compliation database, Technical Report available at: http://pubs.usgs.gov/ds/545, 2010.

Haywood, J. M., Jones, A., Clarisse, L., Bourassa, A., Barnes, J., Telford, P., Bellouin, N., Boucher, O., Agnew, P., Clerbaux, C., Coheur, P.-F., Degenstein, D., and Braesicke, P.: Observations of the eruption of the Sarychev volcano and simulations using the HadGEM2 climate model, J. Geophys. Res., 115, D21212, doi:10.1029/2010JD014447, 2010.

Herman, J. R., Bhartia, P. K., Torres, O., Hsu, C., Seftor, C., and Celarier, E.: Global distribution of UV-absorbing aerosols from Nimbus 7/TOMS data, J. Geophys. Res., 102, 16911-16922, doi:10.1029/96JD03680, 1997.

Hilton, F., Armante, R., August, T., Barnet, C., Bouchard, A., Camy-Peyret, C., Capelle, V., Clarisse, L., Clerbaux, C., Coheur, P.-F., Collard, A., Crevoisier, C., Dufour, G., Edwards, D., Faijan, F., Fourrié, N., Gambacorta, A., Goldberg, M., Guidard, V., Hurtmans, D., Illingworth, S., Jacquinet-Husson, N., Kerzenmacher, T., Klaes, D., Lavanant, L., Masiello, G., Matricardi, M., McNally, A., Newman, S., Pavelin, E., Payan, S., Péquignot, E., Peyridieu, S., Phulpin, T., Remedios, J., Schlüssel, P., Serio, C., Strow, L., Stubenrauch, C., Taylor, J., Tobin, D., Wolf, W., and Zhou, D.: Hyperspectral Earth Observation from IASI: four years of accomplishments, B. Am. Meteor. Soc., 93, 347-370, 2012.

Hofstadter, M., Aumann, H. H., Manning, E., and Gaiser, S.: AIRS Algorithm Theoretical Basis Basis Document, Level 1B, Part 2: Visible/Near-Infrared Channels, Version 2.2, 10 November 2000.

IATA: Press Release: Volcano Crisis Cost Airlines \$1.7 Billion in Revenue - IATA Urges Measures to Mitigate Impact: http: //www.iata.org/pressroom/pr/Pages/2010-04-21-01.aspx, 2010.

ICAO: EUR DOC 9974 - Flight Safety and Volcanic Ash (Advance edition), International Civil Aviation Authority, http://www.icao. int/publications/Documents/9974_unedited_en.pdf, 2012.

Karagulian, F., Clarisse, L., Clerbaux, C., Prata, A. J., Hurtmans, D., and Coheur, P. F.: Detection of volcanic $\mathrm{SO}_{2}$, ash, and $\mathrm{H}_{2} \mathrm{SO}_{4}$ using the Infrared Atmospheric Sounding Interferometer (IASI), J. Geophys. Res., 115, D00L02, doi:10.1029/2009JD012786, 2010.

Krotkov, N. A., Schoeberl, M. R., Morris, G. A., Carn, S. A., and Yang, K.: Dispersion and lifetime of the $\mathrm{SO}_{2}$ cloud from the August 2008 Kasatochi eruption, J. Geophys. Res., Okmok-Kasatochi Special Issue, 115, D00L20, doi:10.1029/2010JD013984, 2010.

Levelt, P. F., van den Oord, G. H. J., Dobber, M. R., Mälkki, A., Visser, H., de Vries, J., Stammes, P., Lundell, J. O. V., and Saari,
H.: The Ozone Monitoring Instrument, IEEE T. Geosci. Remote, 44(5), doi:10.1109/TGRS.2006.872333, 2006.

Miller, C. F. and Wark, D. A.: Supervolcanoes and their explosive supereruptions, Elements, 4, 11-16, doi:10.2113/GSELEMENTS.4.1.11, 2008.

Miller, T. P. and Casadevall, T. J.: Volcanic ash hazards to aviation, Encyclopedia of Volcanoes, edited by: Sigurdsson, H., Houghton, B., McNutt, S. R., Ryman, H., and Stix, J., Academic Press, San Diego, 915-930, 1999.

Munro, R., Eisinger, M., Anderson, C., Callies, J., Corpaccioli, E., Lang, R., Lefebvre, A., Livschitz, Y., and Albinana, A. P. GOME-2 on MetOp, in: Proc. of The 2006 EUMETSAT Meteorological Satellite Conference, Helsinki, Finland, 12-16 June 2006, EUMETSAT P.48, 2006.

Oppenheimer, C., Scaillet, B., and Martin, R. S.: Sulfur degassing from volcanoes: source conditions, surveillance, plume chemistry and impacts, Rev. Mineral. Geochem., 73, 363-421, doi:10.2138/rmg.2011.73.13, 2011.

Platt, U. and Stutz, J.: Differential optical absorption spectroscopy: Principles and Applications., Springer-Verlag Berlin Heidelberg, 2008.

Prata, A. J.: Satellite detection of hazardous volcanic clouds and the risk to global air traffic, Nat. Hazards, 51, 303-324, doi:10.1007/s11069-008-9273-z, 2009.

Prata, A. J. and Bernardo, C.: Retrieval of volcanic $\mathrm{SO}_{2}$ column abundance from Atmospheric Infrared Sounder data, J. Geophys. Res., 112, D20204, doi:10.1029/2006JD007955, 2007.

Prata, A. J. and Prata, A. T.: Eyjafjallajökull volcanic ash concentrations determined using Spin Enhanced Visible and Infrared Imager measurements, J. Geophys. Res., 117, D00U23, doi:10.1029/2011JD016800, 2012.

Prata, A. J., Carn, S. A., Stohl, A., and Kerkmann, J.: Long range transport and fate of a stratospheric volcanic cloud from Soufrière Hills volcano, Montserrat, Atmos. Chem. Phys., 7, 5093-5103, doi:10.5194/acp-7-5093-2007, 2007.

Prata, A. J., Gangale, G., Clarisse, L., and Karagulian, F.: Ash and sulfur dioxide in the 2008 eruptions of Okmok and Kasatochi: Insights from high spectral resolution satellite measurements, J. Geophys. Res., 115, D00L18, doi:10.1029/2009JD013556, 2010.

Rix, M., Valks, P., Hao, N., Van Geffen, J., Clerbaux, C., Clarisse, L., Coheur, P.-F., Loyola, D., Erbertseder, T., Zimmer, W., and Emmadi, S.: Satellite monitoring of volcanic sulfur dioxide emissions for early warning of volcanic hazards, IEEE J. Sel. Top. Appl., 2, 196-206, doi:10.1109/JSTARS.2009.2031120, 2009.

Rix, M., Valks, P., Hao, N., Loyola, D. G., Schlager, H., Huntrieser, H. H., Flemming, J., Koehler, U., Schumann, U., and Inness, A.: Volcanic SO2, BrO and plume height estimations using GOME-2 satellite measurements during the eruption of Eyjafjallajökull in May 2010, J. Geophys. Res., 117, D00U19, doi:10.1029/2011JD016718, 2012.

Robock, A.: Volcanic eruptions and climate, Rev. Geophys., 38, 191-219, doi:10.1029/1998RG000054, 2000.

Robock, A. and Oppenheimer, C. (Eds.): Volcanism and the Earth's Atmosphere, Geophys. Monogr. Ser., 139, 360 pp., AGU, Washington, DC, doi:10.1029/GM139, 2003.

Stohl, A., Prata, A. J., Eckhardt, S., Clarisse, L., Durant, A., Henne, S., Kristiansen, N. I., Minikin, A., Schumann, U., Seibert, P., Stebel, K., Thomas, H. E., Thorsteinsson, T., Tørseth, K., and 
Weinzierl, B.: Determination of time- and height-resolved volcanic ash emissions and their use for quantitative ash dispersion modeling: the 2010 Eyjafjallajökull eruption, Atmos. Chem. Phys., 11, 4333-4351, doi:10.5194/acp-11-4333-2011, 2011.

Surono, Jousset, P., Pallister, J., Boichu, M., Buongiorno, M., Budisantoso, A., Costa, F., Andreastuti, S., Prata, F., Schneider, D., Clarisse, L., Humaida, H., Sumarti, S., Bignami, C., Griswold, J., Carn, S., Oppenheimer, C., and Lavigne, F.: The 2010 explosive eruption of Javas Merapi volcano - a "100year" event, J. Volcanol. Geotherm. Res., 241-242, 121-135, doi:10.1016/j.jvolgeores.2012.06.018, 2012.

Thomas, H. E. and Prata, A. J.: Sulphur dioxide as a volcanic ash proxy during the April-May 2010 eruption of Eyjafjallajökull Volcano, Iceland, Atmos. Chem. Phys., 11, 6871-6880, doi:10.5194/acp-11-6871-2011, 2011.

Thomas, H. E. and Watson, I. M.: Observations of volcanic emissions from space: current and future perspectives, Nat. Hazards, 54, 323-354, 2010.

Torres, O., Bhartia, P. K., Herman, J. R., Ahmad, Z., and Gleason, J.: Derivation of aerosol properties from satellite measurements of backscattered ultraviolet radiation. Theoretical basis, J. Geophys. Res., 103, 17099-17110, 1998.

Tulet, P. and Villeneuve, N.: Large scale modeling of the transport, chemical transformation and mass budget of the sulfur emitted during the April 2007 eruption of Piton de la Fournaise, Atmos. Chem. Phys., 11, 4533-4546, doi:10.5194/acp-11-45332011, 2011.

Van Geffen, J., Van Roozendael, M., Di Nicolantonio, W., Tampellini, L., Valks, P., Erbetseder, T., and Van der A, R.: Monitoring of volcanic activity from satellite as part of GSE PROMOTE, in: Proceedings of the 2007 Envisat Symposium, ESA, Montreux, Switzerland, publication SP-636, 23-27, April 2007, 2007.
Van Geffen, J., Van Roozendael, M., Rix, M., and Valks, P.: Initial validation of GOME-2 GDP $4.2 \mathrm{SO}_{2}$ total columns (OTO/SO2) - ORR B, O3MSAF validation report, TN-IASBGOME2-O3MSAF-SO2-01.1, 2008.

Van Gent, J., Spurr, R., Theys, N., Lerot, C., Brenot, H., Dils, B., and Van Roozendael, M.: Towards an operational $\mathrm{SO}_{2}$ plume altitude algorithm for GOME-2 radiance measurements, Atmos. Meas. Tech. Discuss., in preparation, 2014.

Witham, C. S., Hort, M. C., Potts, R., Servranckx, R., Husson, P., and Bonnardot, F.: Comparison of VAAC atmospheric dispersion models using the 1 November 2004 Grimsvötn eruption, Met. Apps, 14, 27-38, doi:10.1002/met.3, 2007.

Yan, H., Chen, L., Tao, J., Su, L., Huang, J., Han, D., and Yu, C.: Corrections for $\mathrm{OMI} \mathrm{SO}_{2}$ BRD retrievals influenced by row anomalies, Atmos. Meas. Tech., 5, 2635-2646, doi:10.5194/amt5-2635-2012, 2012.

Yang, K., Krotkov, N. A., Krueger, A. J., Carn, S. A., Bhartia, P. K., and Levelt, P. F.: Retrieval of large volcanic $\mathrm{SO}_{2}$ columns from the Aura Ozone Monitoring Instrument (OMI): comparison and limitations. J. Geophys. Res., 112, D24S43, doi:10.1029/2007JD008825, 2007.

Yang, K., Liu, X., Krotkov, N. A., Krueger, A. J., and Carn, S. A.: Estimating the altitude of volcanic sulfur dioxide plumes from space borne hyper-spectral UV measurements, Geophys. Res. Lett., 36, L10803, doi:10.1029/2009GL038025, 2009.

Zehner, C. (Ed.): Monitoring volcanic Ash from Space ESAEumetsat workshop on the 14 April to 23 May 2010 eruption at the Eyjafjallajökull volcano, South iceland, STM-280, ESA/ESRIN, 58 pp., July, 2010. 